Max-Planck-Institut für demografische Forschung

Max Planck Institute for Demographic Research

Konrad-Zuse-Strasse 1 - D-18057 Rostock - GERMANY

Tel +49 (0) 3812081 - 0; Fax +49 (0) 3812081 - 202;

http://www.demogr.mpg.de

MPIDR WORKING PAPER WP 2012-020

JUNE 2012

\title{
Fertility Decline in the southeastern Austrian Crown lands. Was there a Hajnal line or a transitional zone?
}

Peter Teibenbacher (peter.teibenbacher@uni-graz.at)

This working paper has been approved for release by: Mikołaj Szołtysek (szoltysek@demogr.mpg.de), Deputy Head of the Laboratory of Historical Demography.

(C) Copyright is held by the authors.

Working papers of the Max Planck Institute for Demographic Research receive only limited review. Views or opinions expressed in working papers are attributable to the authors and do not necessarily reflect those of the Institute. 
Fertility Decline in the southeastern Austrian Crown lands.

Was there a Hajnal line or a transitional zone?

Peter Teibenbacher

Graz-Austrian-Fertility Project (GAFP), Austrian Science Fund

P 21157 - G15, at the Department for Economic, Social and Business History, Karl-

Franzens-University Graz, Universitätsstraße 157E/2, 8052 Graz, Austria.

E-mail peter.teibenbacher@uni-graz.at, Tel 00433163803523

MPIDR working paper WP 2012-XXXX

\begin{abstract}
There is a substantial body of literature on the subject of fertility decline in Europe during the first demographic transition. Historical demographic research on this topic started in Western Europe, but, as a result of the discussion of the Hajnal line thesis, the decline in fertility has been more thoroughly explored for Eastern Europe (especially Poland and Hungary) than for areas in between, like Austria. This project and this working paper will seek to close this gap by addressing the question of whether the Austrian Crown lands in the southeast represented not just an administrative, but also a demographic border. Using aggregated data from the political districts, this paper will review the classic research about, as well as the methods and definitions of, fertility decline. Our results show that, even the Crown land level, which was used in the Princeton Fertility Project, is much too high for studying significant regional and systemic differences and patterns of fertility changes and decline. This process is interpreted as a result of economic and social modernization, which brought new challenges, as well as new options. Thus, fertility decline should not be seen as a linear and sequential process, but rather as a process driven by the sometimes paradoxical interdependencies of problems and opportunities faced by families and social groups.
\end{abstract}

Keywords southeast Austria, First Demographic Transition, fertility decline 
The current project primarily uses data from Oesterreichische Statistik, the official series of the Austrian Statistical Bureau, which have been compiled since 1881; and from its predecessor, the Austrian Statistisches Jahrbuch, which covers the years 1865 to 1880 . These volumes contain various types of serial data on natural population movement and for the census years $(1869,1880,1890,1900,1910)$, as well as a considerable amount of data on economic, occupational, and social structures (heavy livestock, ethnicities, languages, religions and denominations, literacy, age structures, and other data). In addition, we use a number of printed statistical sources (series, books etc.) that provide socioeconomic structural data on taxes and savings, agricultural outputs, etc. These sources allow us to test different socioeconomic, cultural, and epidemiological theories of fertility decline. However, the religious/denominational aspect (Derosas and van Popel 2006) could not be addressed, both because $98 \%$ of the population were registered as Catholics, and because the members of religious minorities were not concentrated, but were rather scattered over the whole area under research. Unfortunately, valid data on migration are not available at the administrative level of the political districts. The census data do offer some information, but there are considerable uncertainties, as will be discussed later in the paper. This is a pity, because migration influences fertility by changing sex and age ratios not only in the places of origin, but also at the destination. Migrants may, for example, exhibit different fertility patterns than native social groups. ${ }^{1}$

The area under research consists of the Austrian Crown lands of Lower Austria, Styria, Carinthia, Carniola, Gorizia, Trieste, and Istria ${ }^{2}$. The capital of Vienna is treated separately. These Crown lands bordered the Hungarian part of the Hapsburg dual monarchy, and, in a wider sense, Eastern and South-Eastern Europe. Whereas the northern parts of this area were predominantly German-speaking, the most southern part of Styria, today the eastern part of Slovenia, and Carniola were settled by Slovenes; while Gorizia and Istria were settled by a mixture of Italians, Slovenes, and Croats.

Demeny (1972), Coale and Watkins (1986) and Exner (1999) have studied this area. Demeny and Coale considered the provincial level only, while Exner analyzed

\footnotetext{
${ }^{1}$ Cf. Moreels and Vandezande and Matthijs 2010

${ }^{2}$ Gorizia, Trieste and Istria were aggregated to one Crown land, but counted as single statistical units.
} 
fertility in the political districts, using Coales $I_{g}$ (for the 1880 data), but covering the territory of modern-day Austria only. The main results of these studies showed that fertility was fairly high, and that the decline in fertility started late, around 1900, and in high fertility areas first. This paper intends to go beyond these rough findings.

Fig. 1

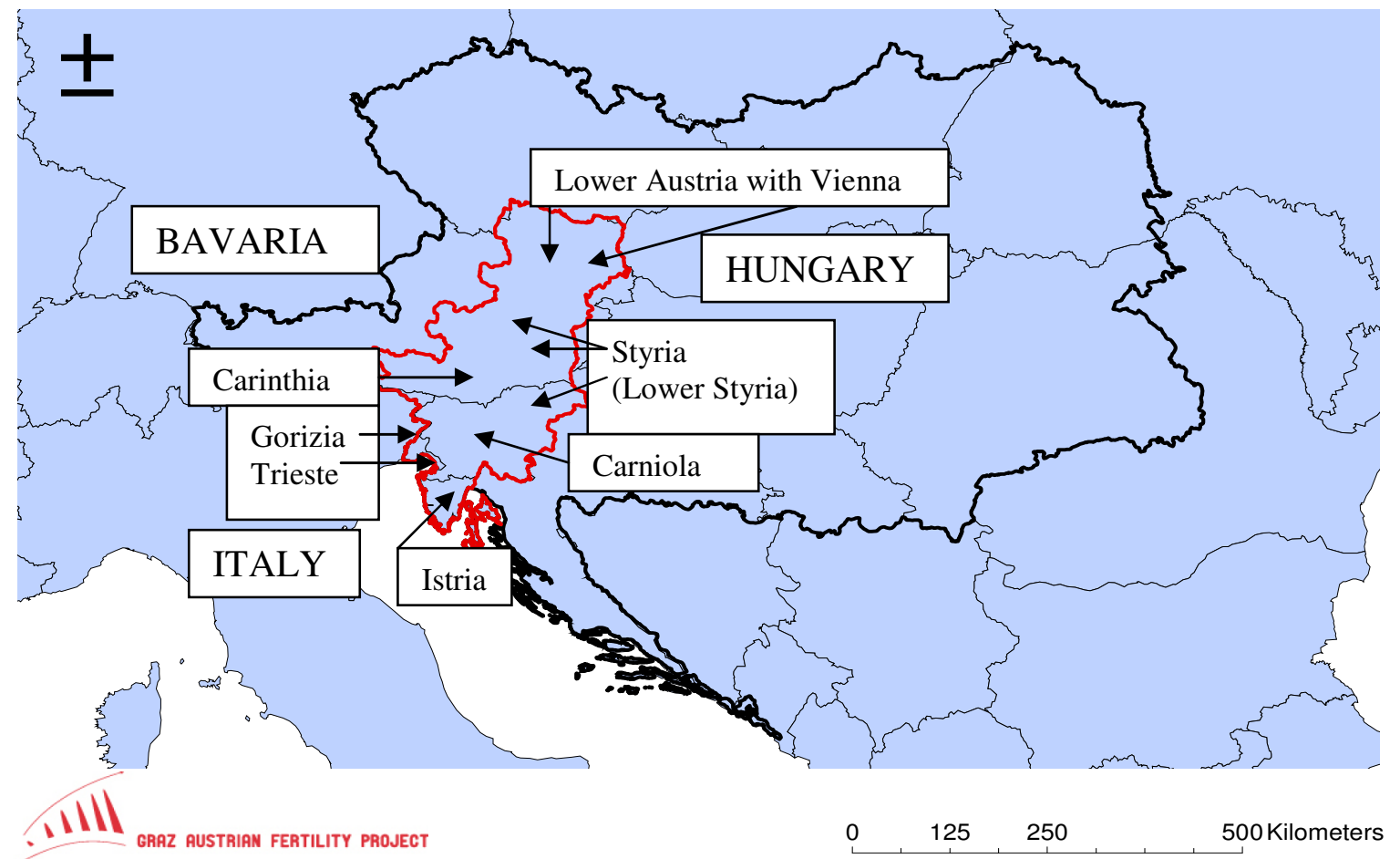

The area from Lower Austria to the Adriatic Sea was home to people who not only had different languages and ethnicities, but who also represented very different ecotypes, ranging from small winegrowers and large grain farmers in Lower Austria, to large heavy-livestock farmers in the mountains of Styria, to small tillers in Slovenia and Carniola, and to fishermen and Mediterranean farmers in the far south. Industries were mostly concentrated in the northern parts. It is also important to note that this part of the monarchy suffered from ethnic tensions. For example, in the far south, in Istria, primary school enrollment rates were very low (up to around two-thirds), not because families did not want their children to go to school, but mainly because nonGerman-speaking parents did not want their children to attend a "German" school. Thus, it could be misleading to associate the subsequent high level of illiteracy with the high level of fertility in this area.

The quality of the data is, generally, very high. Unfortunately not all of the relevant data are available for all of the years; for the 1870s, in particular, some demographic data are not available from these statistics. Data quality differs by region. The 
southern, non-German-speaking areas under research often show a significantly higher instability in demographic data, with annually heavy ups and downs that mostly cannot be explained. The variance level for the whole series is not, however, higher for these areas. The numbers of births, marriages, and deaths had been registered by the priests, and annually summarized tables were delivered to the state's administration. It is possible that these summaries are not exact enough. As there were no civil registers, the priest's summaries were also used by the statistical bureau.

The aggregate level of the data is represented by the political districts. The Crown land of Styria, for example, had about 25 districts. These were, of course, artificial administrative units, but the separate districts represented different systems with their own economic, social, and even ethnic concerns. These districts are more suitable for describing the different systems which influenced the process of fertility decline, as we will show. An analysis at the Crown land level would conceal these striking differences, delivering a raw mean only.

The whole area, from Vienna to the Adriatic Sea, comprised 90-100 political districts, depending on administrative changes. We call refer to this district level as the microregional level (MIRL). The Crown lands (Lower Austria, including Styria, Carinthia, Carniola, Gorizia, Trieste, Istria, with Vienna treated separately) are defined as the macro-regional level (MARL). The original statistics often refer to the traditional regions. Within Styria, for example, references are made to Upper Styria, Styria Midlands, and Lower Styria (after 1918, this region became part of Yugoslavia, and then Slovenia, and is still called Stajerska, or Steiermark). These regions have been used to define a meso-regional level (MERL), resulting in 29 meso-regions, with the towns treated separately. These meso-regions are adjacent, and comprise three to five adjacent political districts, in addition to the towns. They do in fact represent different landscapes, different methods of agricultural production, and varying degrees of industrialization. In Lower Austria, these regions were-and, to some extent, still are-called, for example, the "Vine Quarter" or the "Industrial Quarter" (see the appendix, Figure 4 and Table 22).

These meso-regions also have somewhat different patterns of fertility decline. In this context, it is important to mention that the ethnic and linguistic border roughly followed the current national borders between Austria and Slovenia. The mesoregions with numbers $8,9,10$, and 15 (the Slovenian-speaking part of the Styria Crown land) and 20 to 30 (see Figure 4) were predominantly settled by Slovenes, Italians, and Croats. The other meso-regions were predominantly German-speaking. 
The main goal is to provide a systematic description and structurally oriented explanation of the different regional patterns of fertility (decline), and especially of marital fertility (decline).

To do this, we used two main methods: first, we conducted a regional, serial cluster analysis; and, second, we used a set of statistics to measure fertility decline in greater detail.

The regional, serial cluster analysis was performed with the help of time-series data (1869 to 1913, to the extent that data are available). We use the Ward method, with zstandardization if necessary. The cluster analysis of the political districts uncovered systemic differences in ways of life and in levels of fertility (decline). Unlike a traditional clustering, which catches just one moment in time or one central value of the series (mean, variance etc.), the serial clustering also considered the time effects. Second, we were not satisfied with previous definitions of fertility decline and of the starting points. In general, there are two ways to depict fertility decline: the GFR/GMFR (general fertility rate, general marital fertility rate) and Coale's indices, especially the $I_{g}$, used as a TFR. ${ }^{3}$ We did not exclude non-marital fertility, but we chose to concentrate on marital fertility decline. This is because non-marital fertility did not undergo a separate decline. Instead, as part of the transition, a general decrease in the rates of non-marital fertility was caused by social and economic modernization, which led to more options for marriage (cf. Dribe 2009) and the ability to establish a separate, private household, especially outside the agrarian systems. These systems, regardless of whether they were more egalitarian or more restrictive, generally allowed for fewer opportunities to establish new households. This is because the land was not infinitely divisible. Thus, because the agrarian systems were not growing, the demand for a greater number of professionals, farmers, or skilled craftsmen also did not continue to expand.

Defining fertility as fertility behavior means that the fertility decline was caused by decisions that were made either personally or collectively. It is highly unlikely that a woman would have made the decision to stay celibate while still a girl, or that she would have been forced to do so by restrictive systems, and would then go on to then have a certain number of illegitimate children; or that new generations of women would have decided not to marry, but to have fewer, non-marital children. Because

\footnotetext{
${ }^{3}$ Cf. Coale and Watkins 1986.
} 
out-of-wedlock fertility was seldom a desired phenomenon, we are reluctant to speak of a non-marital fertility decline. While there was a general decrease in fertility, there have been regional exceptions, especially in agrarian regions with a tendency towards non-egalitarianism. Thus, when we refer to fertility decline, we mean marital fertility decline. But what represents a decline? When GMFR or Coale's $I_{g}$ decreased? In our view, that would be too easy. The decline in fertility was not just a question of a lower demand for children, but was also associated with a decline in infant and child mortality (Doepke 2005), at least to the extent that infant/child mortality was high enough to pose a threat. Leaving out the cities, we can see that, in a given year, there was an overall Spearman coefficient (over all of the districts, covering the period 1881-1910) of $.730 * *$ between the probability of a married woman of fertile ages giving birth and facing the death of an infant or a child. Yet this value increased from the 1880 s $\left(.619^{* *}\right)$, and gradually rose as high as $.803^{* *}$ in the 1900 s. The decline in infant/child mortality therefore had a strong impact on marital fertility decline. If, for example, a couple who wanted four children expected one-third of the children born to die, they would need to have six births. If, however, they expected all of their children to survive, they would need only four births. In the end, the number of surviving children would have been the same, namely four, even if the number of births decreased from six to four. Thus, a decline in the number of births does not automatically mean a decline in fertility. We have to differentiate between a gross fertility decline and a net fertility decline. The first type occurs when the number of births is lower only due to the decline in infant/child mortality. This kind of decline is simply filling the gap that opened up when infant (child) mortality decreased. A net fertility decline occurs only when the speed of the fertility decline is higher than that of the decline in infant/child mortality. So far as this was the case persistently, we can speak of a fertility decline.

Summarizing these arguments, we have to conclude that Coale's $I_{g}$ is not suitable for determining regional systemic patterns in fertility decline, and is also not suitable for doing so in a serial manner. Instead, data on age-structured fertility, which are available for the census years and at the level of the Crown lands only, are necessary. Second, we note that the $I_{g}$, and the usual GFR, measure a gross decline in fertility only.

In this project/paper, we will use an AMFR (average marital fertility rate) and a model for calculating the net fertility decline. In addition, we will refer to a gross fertility decline as a fertility loss, and we will reduce the term fertility decline to a net fertility 
decline only. We will discuss the models in detail later on, when presenting the results.

Structural data like age structures, which are available for the census years only, have been annually inserted through a simple, linear interpolation.

The political districts as administrative units did not, of course, remain the same size over time: some have been divided, some have been combined and then divided again at a later date, etc. We have taken into account all of these changes as precisely as possible. The data presented a number of problems because Austrian Statistics sometimes counted the population of a district based on the new borders, but the vital events based on the old borders. This occurred when the changes happened in a census year and the printed edition of the vital statistics had already been completed in the early part of the next year, and thus earlier than the results of the census.

GAFP deals with these demographic data covering the period until 1937, including the province of Burgenland, which became part of the First Austrian Republic in 1922. For some one thousand years, this area had been part of the Hungarian kingdom, and, from 1867 onwards, it belonged to the Hungarian part of the dual Hapsburg monarchy. The project analyzes some of the data for Burgenland that are available for period starting in 1869: namely, the raw birth, death, and marriage rates, which generally show that Burgenland was a high-fertility area.

This paper will, however, present the results for 1869 to 1913 only, disregarding Burgenland, due to the lack of comparable, basic data, like information on marital fertility or infant mortality, for the political districts in this area. Nonetheless, Burgenland would be an interesting area to analyze, as people with different ethnicities (Hungarians, Croats, German Austrians) and religious denominations (Catholics, Lutherans, Calvinists, Jews) lived there.

\section{$3 \quad$ Results}

\subsection{Nuptiality and the rise in marriage rates}

When we look at the social aspects of modernization, we expect to find that, on the one hand, the chances and opportunities to marry and to establish a family and a separate household increased due to the elimination of restrictions (in Austria in 1868, except in Tyrol and Vorarlberg), and due to the creation of new jobs outside of the agrarian regimes. On the other hand, we might also expect to find that the process of 
de-agrarization created new opportunities for women to stay unmarried and earn their own living.

Obviously, we have to differentiate between more egalitarian and more restrictive nuptiality systems. Nuptiality was a social and an economic category. The areas with non-egalitarian, hierarchical systems included the mountainous parts of Styria and Carinthia Crown lands especially. Larger farms with heavy livestock, meadows, pastures, and forests; a single-heir system, formal marriage restrictions (until 1868) and structural marriage barriers for non-housed/landed people were among the characteristics of this system. The large farmers obviously feared that they would be forced by the lord of the manor to divide their land if legitimately born poor made demands for land. ${ }^{4}$ This system was accompanied by a high level of non-marital fertility in part because of the marriage restrictions and barriers, and partly because the illegitimately born children were welcomed as cheap workforce in a nonmechanized mountainous agricultural system. The non-marital fertility rate increased regularly, and even reached levels of 90 births per 1,000 unmarried women of fertile ages at the end of the period under research. ${ }^{5}$ With the help of some nominative datasets, we have concluded that most of these births were by different mothers, and that more than two out-of-wedlock births by the same mother very seldom occurred. Marital fertility in these areas amounted to about 250 per 1,000 women, with the number decreasing or even rising slightly until 1913. In Lower Austria and in the nonGerman-speaking South particularly, we expect to find a more egalitarian system with fewer marriage restrictions or barriers. Especially among the Italians, the Slovenes, and the Croats, it was generally accepted that young people should marry, regardless of how affluent they were. It is possible that marriages were postponed if the actual yearly income on a small farm was too low, but this was only a tactic, and did not represent the long-term strategy. We also know that, in these areas, the partition of land had often been practiced. As a result, the farms had become very small, and temporary out-migration was necessary in order to earn money by any means possible. Peddling was especially widespread, even among the formal holders of the farm, and not just among co-resident siblings. ${ }^{6}$ But there was another, very traditional issue. As early as in 1492, Emperor Friedrich III allowed subservient individuals in Carniola to leave the manorial area and even the country temporarily in order to earn

\footnotetext{
${ }^{4}$ Cf. Ehmer 1991.

${ }^{5}$ Illegitimacy had always been higher in these areas and in this agricultural ecotype, but there was a significant increase during the second half of the $18^{\text {th }}$ century, cf. Teibenbacher 2010; Sumnall 2009 and 2010; Mitterauer 1983.

${ }^{6}$ Cf. Rigler and Rozman 2010.
} 
money as peddlers, tradesmen, etc. This was in response to the devastation of huge parts of the country by the wars against the Ottomans. This privilege was regularly renewed by subsequent kings and emperors upon the request of the people, even though there were no more wars in this area. It was, for example, renewed in $1841 .^{7}$ It is possible that this option of leaving and earning money elsewhere hindered a sustainable, structural advancement of the agrarian system in Carniola and consolidated traditional features, including demographic ones. These traditions may have affected the attitudes of the lords of the manor as well as of the farmers.

In general we can say that, the smaller the agrarian unit-including smallholders like winegrowers or fishermen-the more open and the less restrictive the nuptiality system was. We cannot confirm that the small size was caused by the openness of the nuptiality system (entailing the partition of land), because it is also possible that the small size led to greater openness in attitudes. People who do not have much to lose are less afraid of allowing others to participate in the system.

The process of social and economic modernization, the elimination of formal marriage restrictions, and the creation of new jobs obviously caused an increase in the number of marriages. This happened especially in those predominantly agrarian areas in which access to marriage had previously been restricted, and in the industrial and urban areas to which many people from the countryside migrated, and then took advantage of the new opportunity to earn money, to marry and establish a separate, private household. This was, in a sense, a catch-up process.

It should be noted that being allowed to get married was associated with social advancement, especially for a woman. Historically, the lower classes would have recognized that marriage provided an opportunity for social advancement, such as when marriage occurred between the farmer and the farmhand, the burger and the housemaid, or the master and the apprentice. To be married and to have a family with children surely represented a kind of social integration. In areas with few or no strategic marriage restrictions, marriage was viewed from the opposite perspective, and the probability of marrying decreased slightly or remained stable. However, nonmarital fertility and illegitimacy did not increase in these areas.

\footnotetext{
${ }^{7}$ Afterwards it was no longer necessary, as in 1867 the Staatsgrundgesetz allowed everybody to work in any job and in any location.
} 
Table 1: Probability of women aged 14-44, being celibate at the beginning of the year to be married by the end of the year (mean per decades), in selected meso-regions, per 1000

\begin{tabular}{|l|l|l|l|}
\hline Meso-regions & $\begin{array}{l}1881- \\
1890\end{array}$ & $\begin{array}{l}1891- \\
1900\end{array}$ & $\begin{array}{l}1901- \\
1910\end{array}$ \\
\hline Vienna & 47,7 & 58,9 & 54,6 \\
\hline Wine Quarter (Lower Austria) & 55,1 & 49,0 & 51,8 \\
\hline Industrial Upper Styria & $\mathbf{4 4 , 6}$ & $\mathbf{5 4 , 3}$ & $\mathbf{5 8 , 6}$ \\
\hline Agrarian Upper Styria & $\mathbf{3 0 , 2}$ & $\mathbf{3 8 , 2}$ & $\mathbf{4 0 , 6}$ \\
\hline Carinthia Midlands & $\mathbf{2 8 , 4}$ & $\mathbf{3 3 , 1}$ & $\mathbf{3 8 , 9}$ \\
\hline Southern Styria & 40,4 & 39,1 & 38,6 \\
\hline Lower Styria & 48,6 & 48,8 & 44,8 \\
\hline Inner Carniola & 61,6 & 60,1 & 58,8 \\
\hline Trieste & 53,5 & 50,6 & 55,7 \\
\hline Istria Islands & 66,6 & 68,3 & 68,7 \\
\hline Bold: regin wib cat & & \\
\hline
\end{tabular}

Bold: regions with a catch-up process; italics: non-German-speaking areas

As the chances of getting married increased, the first marriage age decreased, following the same conditions (s. Table 2). We clearly cannot expect that these "new" and young marriages would have been childless. Table 1 also shows that there were ethnic/linguistic and social-occupational criteria. In the non-German-speaking areas in the south, the very small farmers, who were often temporarily engaged in peddling, faced a decrease in the probability of marriage, but they had always had higher values. The German-speaking smallholders (winegrowers) in the Wine Quarter in eastern Lower Austria also displayed a higher probability, which indicates a low level of strategic marriage restrictions. Obviously, it was the social character of the smallholding which prevented the imposition of marriage restrictions. Agrarian smallholding was the predominant social feature in the non-German-speaking south, and thus the relationship between language and nuptiality system appears to have been strong. This argument is supported by the values for the adjacent meso-regions of Southern Styria and Lower Styria. Southern Styria had much smaller agrarian units than the meso-region of agrarian Upper Styria, but larger units than was typical in the Slovenian-speaking area of Lower Styria. The values of the smallholders (fishermen, Mediterranean agrarians, olive cultivators, winegrowers, etc.) on the Istria islands also confirm this assumption. 
It must have been part of the social identity of these agrarian smallholders to marry and to have a large number of children, knowing that there were a great number of structural barriers to marriage for non-owners in agrarian societies elsewhere.

Table 2: Mean marriage age, female (mean per decade)

\begin{tabular}{|l|l|l|l|}
\hline Meso-regions & $\begin{array}{l}1881- \\
1890\end{array}$ & $\begin{array}{l}1891- \\
1900\end{array}$ & $\begin{array}{l}1901- \\
1910\end{array}$ \\
\hline Vienna & 25,4 & 25,4 & 25,3 \\
\hline Wine Quarter (Lower Austria) & 25,8 & 25,5 & 25,3 \\
\hline Industrial Upper Styria & $\mathbf{2 5 , 6}$ & $\mathbf{2 5 , 4}$ & $\mathbf{2 5 , 3}$ \\
\hline Agrarian Upper Styria & $\mathbf{2 6 , 1}$ & $\mathbf{2 5 , 8}$ & $\mathbf{2 5 , 6}$ \\
\hline Carinthia Midlands & $\mathbf{2 5 , 8}$ & $\mathbf{2 5 , 5}$ & $\mathbf{2 5 , 2}$ \\
\hline Southern Styria & 25,8 & 25,8 & 25,8 \\
\hline Lower Styria & 24,9 & 25,1 & 24,9 \\
\hline Inner Carniola & 24,4 & 24,0 & 24,1 \\
\hline Trieste & 24,9 & 24,5 & 24,6 \\
\hline Istria Islands & 23,5 & 23,2 & 23,0 \\
\hline Bold: regions wit aca & & & \\
\hline
\end{tabular}

Bold: regions with a catch-up process; italics: non-German-speaking areas

These tendencies and regional differences are, of course, mirrored in the percentages of married women at fertile ages (see Table 3).

Tables 1-3 clearly show the different marriage systems that existed in this area. While it is clear that the percentages of married woman aged 20-44 did not reach the values found in more eastern or southern parts of Europe, there were significant connections between smallholding and higher percentages of married women, lower ages at marriage, and the probability that celibate women would be married by the end of a given year.

The results also show that there was a strong tie between smallholding and not belonging to German-speaking areas, with the exception of the winegrowers in the Wine Quarter in Lower Austria. To a certain extent, this is reminiscent of Mitterauer's (2004) attempt to explain for the differences in the nuptiality and marriage patterns in Western and Eastern Europe. He argued that the dominance or absence of feudalism and the Hufenverfassung (hide system) was the decisive factor: the more feudal the socioeconomic system, the greater the marriage restrictions and the higher marriage age. 
Table 3: Percentages of married women aged 20-44 (mean per decade)

\begin{tabular}{|l|l|l|l|l|}
\hline MERL & $\begin{array}{l}1871- \\
1890\end{array}$ & $\begin{array}{l}1881- \\
1890\end{array}$ & $\begin{array}{l}1891- \\
1900\end{array}$ & $1901-1910$ \\
\hline Vienna & 42,6 & 43,7 & 46,3 & 48,5 \\
\hline Wine Quarter (Lower Austria) & 52,8 & 52,0 & 52,3 & 53,8 \\
\hline Industrial Upper Styria & $\mathbf{4 0 , 2}$ & $\mathbf{4 2 , 2}$ & $\mathbf{4 5 , 9}$ & $\mathbf{5 1 , 8}$ \\
\hline Agrarian Upper Styria & $\mathbf{3 2 , 8}$ & $\mathbf{3 4 , 5}$ & $\mathbf{3 8 , 1}$ & $\mathbf{4 2 , 2}$ \\
\hline Carinthia Midlands & $\mathbf{3 0 , 6}$ & $\mathbf{3 2 , 1}$ & $\mathbf{3 5 , 8}$ & $\mathbf{4 0 , 5}$ \\
\hline Southern Styria & 44,4 & 44,4 & 44,7 & 46,4 \\
\hline Lower Styria & 50,0 & 49,7 & 50,3 & 51,4 \\
\hline Inner Carniola & 57,6 & 57,3 & 58,4 & 60,0 \\
\hline Trieste & 51,0 & 51,1 & 50.9 & 52,7 \\
\hline Istria Islands & 61,2 & 60,0 & 58,6 & 59,6 \\
\hline
\end{tabular}

Bold: regions with a catch-up process; italics: non-German-speaking areas

For our area, where feudalism was predominant everywhere, we have to substitute the term feudalism/hide system with the term non-smallholding: thus, the more nonsmallholders, the higher the marriage age, the lower the marital fertility, the higher the non-marital fertility, etc. These are the characteristics of a non-egalitarian system (Fauve-Chamoux 2011). Of course, this was a general tendency only; the more mountainous the landscape, the more true this rule became. In Lower Austria, we can find different forms, including more smallholders (Landsteiner and Langthaler 1997) north of the Danube (Wine and Forest Quarters) and fewer smallholders in the southern parts of the Crown land. Here, too, this general rule applies: in the agrarian area south of the Danube (Cider Quarter) we find more non-smallholders, lower marital fertility, and higher non-marital fertility than in the other parts of the Crown land. In the mountainous parts of Styria and Carinthia, these characteristics were even more pronounced. This was the inter-regional pattern, and each region had its own variation on this pattern. Therefore, an overall, interregional correlation or regression coefficient does not really work. Because of the regional variations, these coefficients tend to be rather low, although the basic rules and patterns persist.

Using "smallholder" as a decisive criterion is difficult, as winegrowers and fishermen are definitely smallholders. For farmers, the median farm size could be an indicator. Unfortunately, however, the data available from the printed statistics are too fuzzy, as all agrarian units from 2 ha up to 10 ha had been aggregated into one category, and 
the differences are hidden starting at a size of about 5 ha. Thus, we are using the heavy livestock unit to distinguish between large and small farms, with the data stemming from the different censuses in which occupations and livestock were also counted. We decided to take the number of male individuals in agriculture as the number of farms, and computed the heavy livestock unit, not including horses, adding at least one unit to the resulting number, thus assuming the presence of one horse per farm. This calculation is necessary because there may have been a large estate in a region, which would have had many horses. Thus the results could be distorted. Using the mean of the five values for the census years $(1869,1880,1890,1900,1910)$ we can find a non-parametric negative correlation $\left(-.709^{* *}\right)$ between nuptiality (portions of married women, 20-44 years old) and the averaging number of heavy livestock per farm. The correlation is not linear; but highly significant. The trend is evident in Lower Austria (between the meso-regions in Lower Austria), although the differences are smaller there. The differences between the meso-regions are striking in the Crown lands of Styria and Carinthia, where large areas were dominated by bigger farms with significant numbers of heavy livestock.

In sum, we found that there was a catch-up process in those areas which had a traditional and strategic means of imposing marriage restrictions and/or structural marriage barriers. Obviously, marriage represented a form of social advancement, especially for a woman. Being married was still an indicator of having achieved social acceptance and respect. In the cities we can expect to find that increasing numbers of women decided to remain single, as they could have their own jobs and provide for themselves. However, data from Vienna and Trieste and other cities do not really support this hypothesis, as in the cities the percentages of married women increased (see Table 3). This suggests that there were no strong barriers to marriage. On the other hand, women working in domestic services or the third sector accounted for a large percentage of non-marital births.

All in all, one central criterion of modernization, the equalization of regional differences, was generally fulfilled. Looking at around 100 political districts, we can see that the percentages of married women among all women aged 20 to 44 was $50,3 \%$ in the 1870 s and $52,9 \%$ in the 1900 s, while the STDV was 10.1 and 6.9. 


\subsection{Marriage and seasonality}

Another feature associated with the process of modernization is seasonality of marriages. Different hypotheses connect marrying dates in pre-modern times and during the agrarian era, with the agricultural season or canonic rules (Pfister 2007, Ehmer 2004). Thus we can expect to see peaks in marriage in the late autumn and winter, except during religious fasting periods. In this season, which generally lasted from November to February, outdoor work was reduced to a minimum, and, especially in late autumn, there was more food and possibly more money available from selling harvested agrarian products from the fields or cattle. With the dissolution of agrarian structures and the reduction in the number of people belonging to the first sector, and with secularization, we can expect to see a more equal distribution of marriages/weddings over the whole year, creating peaks during times like the "merry month of May."

Unfortunately, we have seasonal data on marriages for a relatively short period only: namely, for the years 1881 to 1894 . It is, therefore, not possible to discern long-term trends (like Dribe and Putte 2011), and no significant regional changes in the seasonal distribution of marriages during these years can be seen.

Table 4: Seasonality of marriages, monthly means 1881 to 1894 , in percentages

\begin{tabular}{|l|l|l|l|l|}
\hline Meso-regions & Oct & Nov+Jan+Feb & Dec & May \\
\hline Vienna City & 7,5 & 42,5 & 1,4 & 10,9 \\
\hline Wine Quarter (Lower Austria) & 6,7 & 48,1 & 0,4 & 12,2 \\
\hline Industrial Upper Styria & $\mathbf{8 , 7}$ & $\mathbf{4 5 , 1}$ & $\mathbf{0 , 2}$ & $\mathbf{1 1 , 4}$ \\
\hline Agrarian Upper Styria & $\mathbf{9 , 3}$ & $\mathbf{4 5 , 3}$ & $\mathbf{1 , 3}$ & $\mathbf{1 3 , 1}$ \\
\hline Carinthia Midlands & $\mathbf{8 , 3}$ & $\mathbf{5 3 , 1}$ & $\mathbf{0 , 6}$ & $\mathbf{8 , 3}$ \\
\hline Southern Styria & 6,2 & 44,5 & 0,3 & 11,4 \\
\hline Lower Styria & 4,8 & 62,0 & 0,4 & 8,0 \\
\hline Inner Carniola & 6,1 & 48,4 & 0,3 & 10,2 \\
\hline Trieste City & 8,6 & 41,5 & 1,9 & 8,6 \\
\hline Istria Islands & 7,9 & 62,8 & 1,8 & 5,5 \\
\hline
\end{tabular}

Bold: regions with a catch-up process; italics: non-German-speaking areas 
Table 4 shows very traditional patterns of seasonality. The percentage of weddings performed in winter-not including December, which is a fasting month-was between $40 \%$ and $62 \%$. In line with expectations, towns had lower, yet the major percentages also for these months. This was most likely because people living in towns, along with the agrarian population, were dependent on the food supply from the countryside. On the other hand, the fasting month of December, followed by March, were the least popular months for getting married everywhere. February, or carnival time, was the most popular month for getting married, followed by November. Socio-cultural, and especially religious factors therefore also played a role, in addition to economic considerations. However, it is impossible to know, especially in the towns, whether it was because of the people's religiosity or the priests' reluctance to perform a wedding during the fasting periods, like in December, so that dates were set during the carnival season. The latter may have been the case, because in Hapsburgian Austria Catholics could not be legally married (and $98 \%$ of the population in Austria were Catholics) without a church wedding. ${ }^{8}$ May and October are-after November and February—-the single months with the next highest numbers of marriages, but their shares were much lower. October could be considered part of the "post-harvest" season, and May could have already been seen as a "Merry Month." However, due to the movability of Easter, it is likely that May would have been the first fully available marriage month after the fasting period.

The seasonality of marriages was only partially matching the seasonality of birthing (s. chapter 3.5).

\subsection{Marital fertility and its decline}

In the 1980s, the Princeton Fertility Project introduced new, innovative indices for measuring natural population movements (Coale and Watkins 1986). However, because of the data available, it is not easy to use these indices, especially the $I_{g}$, for our area of research. The age structures of childbearing women are given only for the census years and at the Crown land level in the aggregate statistics.

\footnotetext{
${ }^{8}$ Gesetz über die Ehen der Katholiken im Kaiserthum Österreich vom 8. Oktober 1856 (Reichsgesetzblatt, Z. XLVI, Num. 185)
} 
Thus, there are certain disadvantages associated with the $\mathrm{I}_{\mathrm{g}}$.

- the $I_{g}$ cannot be drawn as a series, it conceals e.g. ski-jumps;

- the $I_{g}$ cannot uncover significant regional disparities;

- the $I_{g}$ is - as a TMFR—oriented on Hutterite fertility, which changed over times and never was the highest level of fertility;

- the $I_{g}$ does not consider infant/child mortality and depicts a gross fertility decline only.

The first problem can be solved when dividing the GMFR (general marital fertility rate) by the factor 0.410, as Wetherell (2001) has suggested. Applying this method to our data, the micro- and meso-regional disorientation of the $\mathrm{I}_{\mathrm{g}}$ becomes evident.

Table 5: GMFR and $I_{g}$ in 1900

\begin{tabular}{|l|l|l|l|}
\hline Political District (meso-region) & GMFR/0.410 & Crown land & $\mathrm{I}_{\mathrm{g}}$ \\
\hline Vienna (Town) & 0.468 & Lower Austria & 0.543 \\
\hline Leoben (ind. Upper Styria) & 0.549 & Styria & 0.641 \\
\hline Murau (agr. Upper Styria) & 0.649 & Styria & 0.641 \\
\hline Feldbach (Southern Styria) & 0.644 & Styria & 0.641 \\
\hline Loitsch (Inner Carniola) & 0.836 & Carniola & 0.827 \\
\hline Lussin (Istria islands) & 0.626 & Istria & 0.773 \\
\hline
\end{tabular}

Table 5 shows the comparison of the district and the Crown land levels for the capital of Vienna (about 1.5 million inhabitants); a heavily industrialized district (Leoben); a conservative, non-egalitarian agrarian district with a niche system (Murau); a semiegalitarian district with smaller tillers (Feldbach); and two non-German-speaking districts with agrarian smallholders, an egalitarian marriage system, and the highest $I_{g}$ (Loitsch in Inner Carniola and Lussin, which included the islands in the Adriatic sea). Because the Princeton Project did not consider Vienna as a separate unit, the value for Lower Austria is significantly distorted. Vienna belonged to the Crown land of Lower Austria, but was always registered with own data in the Austrian statistics. The $\mathrm{I}_{\mathrm{g}}$ of Styria seems to be represented by the GMFR/0.410, but this is really a misunderstanding. Murau was never representative of all of Styria, just of a very mountainous part in Upper Styria. For the industrial Leoben and the agrarian Lussin, the $I_{g}$ for the Crown land obviously overestimates regional fertility (Hoem and Mureşan 2011), as these districts were very unusual within their Crown lands (Styria or Istria). 
Instead of Hutterite fertility, which is not the highest level of fertility ever observed, we use an absolute limit, which does not change over time. It is assumed that, naturally, a married woman can give birth to one child every two years. Setting a minimal first marriage age of 20 results in a number of 12.5 children up to the age of 45. This value is in line with the natural value observed among Hutterite women, which was estimated at a TFR of 12 children by the Princeton project (PPP).

It is very easy to assess the deviation of real fertility from this maximal value:

$\mathrm{RMF}=\left(\mathrm{B} /\left(\mathrm{W}_{\text {married, } 14-44 / 2)}\right) * 100\right.$

RMF means realized marital fertility, $\mathrm{B}$ is the empirical number of births (both live births and stillbirths, because stillbirths are also the result of fertility), and W represents married women aged 14 to 44 . The resulting number can be interpreted as the percentage of maximal fertility realized by the number of births observed. The negative annual distances of this number to 100 (RMF-100) can be interpreted as fertility loss against the maximal fertility assumed.

Graph 1: Marital fertility loss in selected meso-regions (RMF-100)

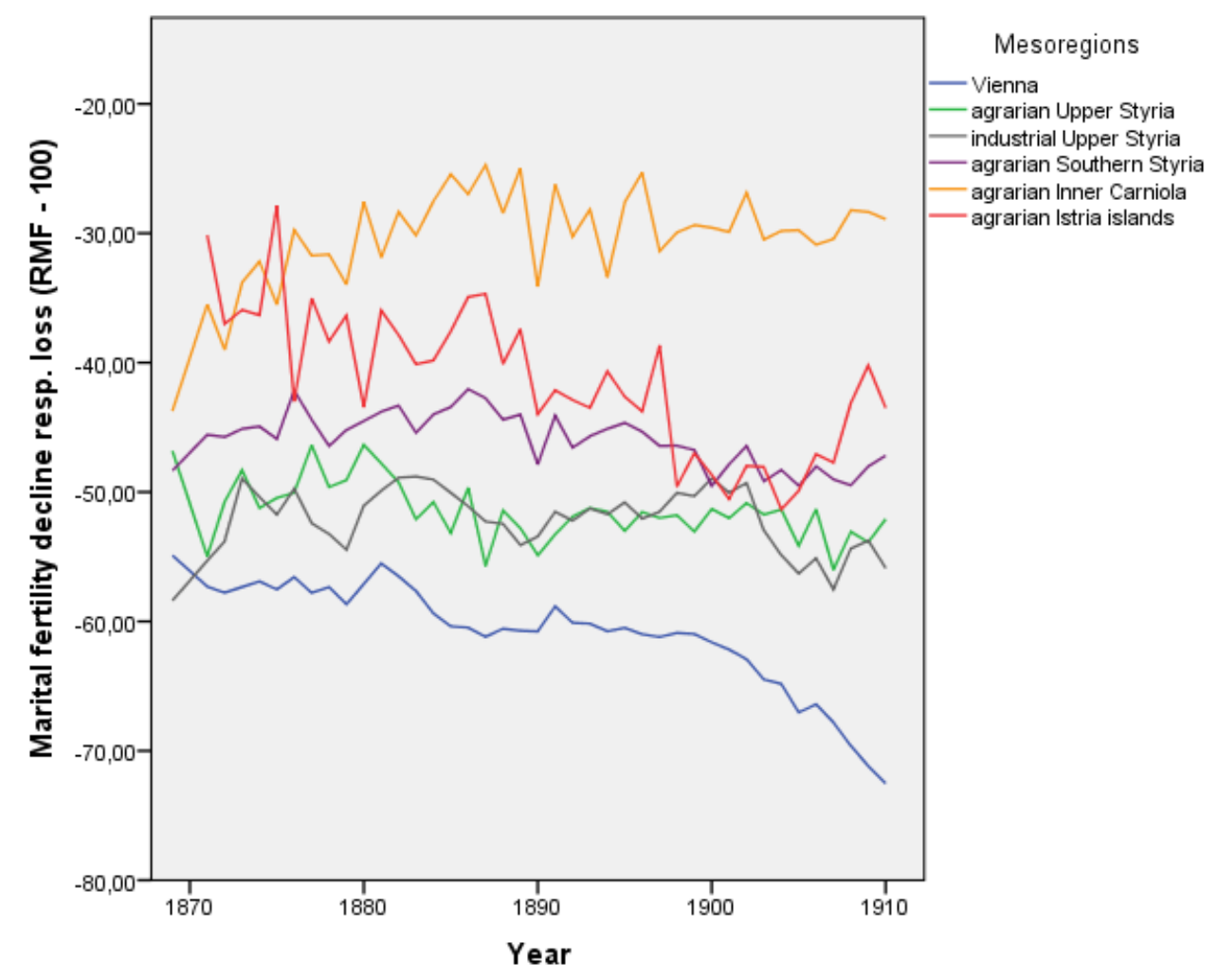


Graph 1 depicts the meso-regions to which the districts listed in Table 4 belonged. Decreasing lines represent a fertility decline-better defined as a fertility lossbecause the RMF does not consider infant/child mortality, and shows only a gross fertility decline. For example, in 1910 the city of Vienna lost about $73 \%$ relative to maximal fertility, which was reached by only $27 \%$. In 1869 , the value was about $55 \%$, thus the relative loss amounted to $18 \%$ for this period of 41 years, or $0.44 \%$ per year.

Graph 1 shows rather persistent, and mainly very slight declines/losses in all of the meso-regions, while the industrialized region (districts in Upper Styria) exhibits a marked increase in the 1890s and early 1900s, followed by a strong decrease. In Vienna and on the Istria islands, the loss was even more pronounced. It is well-known that in the towns the demographic transition (fertility decline) started earlier and was more persistent, largely due to the increasing cost of housing and education, as well as a shift in preferences among workers and white-collar professionals from quantity to quality. They wanted their children well-equipped and well-educated, and therefore tried to avoid capital dilution: it was better to have two children who were welleducated than four children who were poorly prepared for life in an advanced economy. There was also a regional system of a different kind which led to fertility losses among smallholders. The smallholders, represented in Graph 1 by the fishermen and Mediterranean agrarians on the Istria islands, faced the problem of having to feed the large number of children resulting from high levels of fertility, and, due to breastfeeding, relatively low infant mortality. The levels of child mortality were higher than in other areas under research due to a lack of medical supplies on the rather isolated islands, but child mortality normally was much lower than infant mortality, and thus an overall surplus appeared. The islands were partially rocky and there were few or no opportunities to intensify or extend agrarian production. As a consequence, the islands experienced high levels of out-migration. These are, obviously, two different sources of fertility loss, with modernized decision-making taking place in towns, and a natural threat of overpopulation occurring on the Istria islands. Both, however, resulted in pressure on the population. The agrarian Upper Styria region (together with Carinthian regions, especially the Carinthian Midlands) was dominated by larger farmers who pursued a niche strategy that involved raising heavy livestock and employing a large number of non-related farmhands who mostly remained celibate while in service. The probability of marrying increased in these meso-regions, and "new" and young marriages were contracted as part of a catch-up process. However, even the marital fertility of traditional farmers, which was lower on 
an average than in other regions, grew somewhat. This may have been a reaction to the large out-migration from these regions into neighboring industrial sites.

The industrialized meso-regions experienced an even more pronounced catch-up process because most of their in-migrants stemmed from the countryside and from lower strata. They took advantage of the opportunity to marry and have legitimate children, seeing marriage as a form of social emancipation and inclusion. However, as in the towns, the cost effects became apparent for these workers earlier than for the farmers. Thus, the sharp rise, which took place in the 1890s, halted in the early 1900s, and the transition started quickly.

The meso-region of agrarian Southern Styria was dominated by smaller tillers, who cannot, however, be classified as smallholders. They also show a slight decline/loss in fertility. As market-oriented tillers who provided a large portion of the supplies consumed by the country's capital of Graz, they also faced the cost effects of having children, but their fertility had not been as high as that of the smallholders. While there were no sharp rise triggered by - not existing - in-migrants in these areas and less marriage restrictions, there may have been a less dramatic catch-up process and only some degree of compensation for out-migration.

At first glance, and at least for the 1870s and 1880s, the meso-region of Inner Carniola showed a marked increase in fertility, or, rather, a reduction in losses relative to the assumed maximal number of births. On the other hand, even the other agrarian meso-regions-with the exception of extreme cases like that of the Istria islandsexperienced slight increases until 1890 (agrarian Upper Styria and agrarian Southern Styria). These moderate increases appear to have been characteristic of the agrarian regions, and can be found throughout Lower Austria for all of the agrarian mesoregions also.

In short, Demeny's (1972) finding from 40 years ago still holds true: the fertility decline started first in the towns and then in the agrarian regions with higher fertility. These regions were also dominated by smaller tillers or smallholders. Obviously, they reduced their fertility in response to the population pressure caused by traditionally high fertility.

Why, then, did fertility in these regions rise in the 1870s and 1880s? Whereas in these regions of Lower Austria (Wine Quarter and Forest Quarter) and to a certain extent in agrarian Southern Styria, fertility evidently started to decrease persistently in the late 1880 s, this was not the case in Inner Carniola or in the-very different from Inner Carniola-conservative, agrarian, heavy-livestock regions in agrarian Upper Styria 
and Carinthia. Fertility remained stable there until the eve of World War I. What could have been the common factor in the agrarian regions that accounts for this increase? We can observe a general increase in raw birth rates in Austria in the 1860s and 1870s, after a long and marked decrease during the first half of the $19^{\text {th }}$ century. This decrease has not yet been fully explained, but it was probably associated with the wars against France and the subsequent economic downturns during the so-called "Vormärz." Thus we could interpret the increase from about 1850 onwards (the manorial system had been abolished in Austria in 1848) as a period of recovery, followed by a phase of stability in the 1880 s and 1890 s, before the transitional process started at the very end of the $19^{\text {th }}$ century. Carniola shared this basic pattern, but fertility there was higher in general, and the transitional process started later throughout the whole non-German-speaking south, except in the special case of the Istria islands. For Carniola and Gorizia, Demeny's finding of an earlier decline in fertility in areas with a tradition of high fertility do not match. It is likely that the market orientation in these places was too weak. The small, market-oriented tillers in Southern Styria near the capital of Graz and those in Lower Austria also obviously faced cost pressures earlier. In the other parts of Styria, in the livestock-oriented economy of Upper Styria and in the industrial regions of Upper Styria, we do not see an early start in the late 1880 s due to catch-up processes, which should have led to large increases. Again, it appears that the Crown land level is much too high to allow us to detect, differentiate, and understand the different demographic patterns triggered by different life systems consisting of different socioeconomic and socio-cultural factors. The importance of out-migration should not be underestimated. Graz played a decisive role as point of attraction for all of Southern Styria, as did Vienna, especially for the eastern and northern parts of Lower Austria. Younger people and couples in their twenties, who generally have higher fertility, tended to leave, while the middleaged stayed.

Using the RMF, we can also conclude that a maximal level of marital fertility has been reached when, in a given year, $50 \%$ of the married women aged 14-44 gave birth to a child, regardless of whether the child was living or a stillbirth. Figure 2 gives an overview of these percentages (RMFp) in 1900. The assumed maximal value (50\%) was never reached in any region, as the absolute highest numbers lay between $40 \%$ and $45 \%$. The figure also depicts certain lines in the discussion that are assumed to divide European regions in terms of different demographic patterns (Kaser 2000; Reher 1998; Szoltysek 2007 and 2008). 
The figure illustrates that for example low values can be associated with very different conditions and systems in the background. In the light-green area we find districts or meso-regions, dominated by a traditional agrarian niche system and industrial regions also, that had already entered into a transitional process. In the yellow areas we find agrarian districts or meso-regions that were undergoing a marked catch-up process (increasing nuptiality and fertility), as well as regions dominated by small tillers that had already entered the transitional process.

The situation is very clear in the south, which was predominantly agrarian, and populated by very small tillers and smallholders who earned additional money through temporary peddling. These areas show the highest fertility and no indicators for a persistent decline. Because these regions also were non-German-speaking (Slovenes, Italians, Croats), we could be tempted to associate high fertility with Slavic ethnicities. As we have shown earlier, fertility was primarily a social issue, as high fertility was associated primarily with smallholders, and secondarily only with ethnicity. It is always dangerous to connect social behavior with less changeable characteristics like language or ethnicity, as this can encourage prejudice and discrimination. However, living together in poverty can lead to the development of class consciousness, and living together in poverty while belonging to the same ethnicity can lead to the development of ethnic consciousness. Under these conditions, a socio-ethnic culture may arise that sees poverty and ethnic identity as the same issue, from both an internal and an external perspective.

The Reher line, which runs through Geneva and Budapest, also roughly corresponds with the ethnic and linguistic border between the German Austrians and non-Germans in this area (see Figure 4). The map gives a snapshot from 1900 only, revealing, for example, that starting in the 1870 s, there was a gross decline in marital fertility among the smallholders in the northeast (very small farmers and winegrowers in the north of Lower Austria) and in the far south (fishermen and Mediterranean agrarians on the Istria islands). On the other hand, the map hides the fact that, in the mountainous areas in Upper Styria and Carinthia, marital fertility actually increased, starting in the 1870s. 
Fig. 2: RMFp in 1900, in political districts

\section{Hajnal-line}

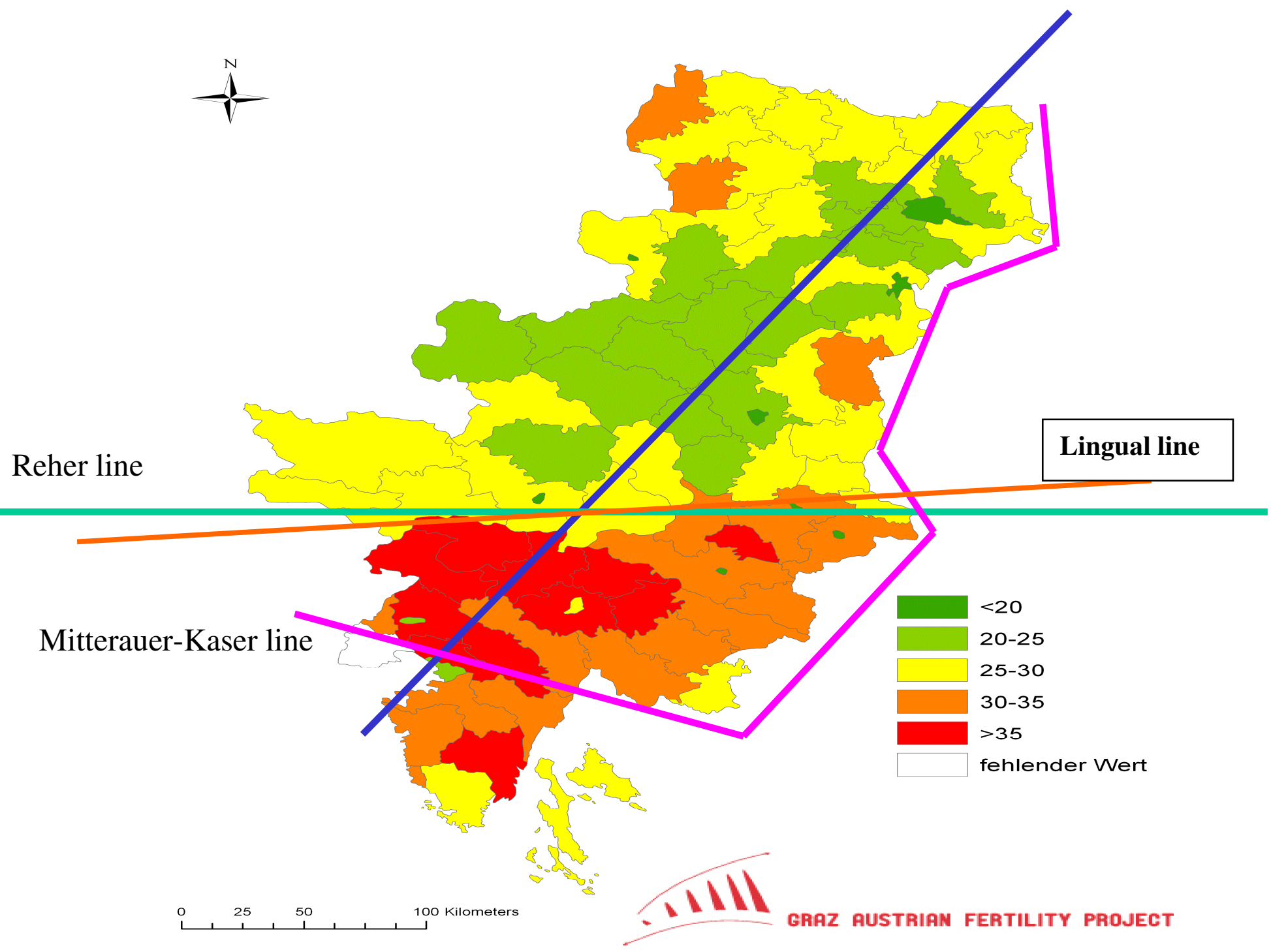

The orange linguistic line in Fig. 2 marks the border between German-speaking areas in the north and non-German-speaking countries in the south.

\subsubsection{Marital net fertility decline}

The classical measures, like GMFR, MTFR, or the $\mathrm{I}_{\mathrm{g}}$; and measures proposed in this paper, like RMF and RMFp; do not take into account infant/child mortality, which obviously played a role in this process of fertility decline (Doepke 2005). To the extent that fertility and infant/child mortality decrease in parallel, there is no net fertility decline, but rather an absolute, gross fertility decline only, which we prefer to 
call a fertility loss. Dribe and Scalone (2011) used the CWR as an indicator for net fertility decline because, when measured as a series, the number of existing children indicates the survival status. However, the CWR does not measure net fertility itself. Using the concept of RMF, assuming a maximal fertility of one child every two years per married woman aged 14-44, we can assume that a maximal level of infant/child mortality would mean that one infant/child would die every two years per married woman aged 14-44.

$\mathrm{RMF}=\left(\mathrm{B} /\left(\mathrm{W}_{\text {married, }} 14-44 / 2\right)\right) * 100$ and $\mathrm{RMD}=\left(\mathrm{D}_{<5} /\left(\mathrm{W}_{\text {married, }} 14-44 / 2\right)\right) * 100$

RMD (realized marital infant/child death) represents the percentage of observed infant/child deaths based on an assumed maximum of infant/child deaths per woman. An annual change in this RMD in comparison to an annual change in RMF, assuming a decline, gives us the net fertility decline $\left(\mathrm{NMF}_{\mathrm{d}}\right)$ :

$\mathrm{NMF}_{\mathrm{d}}=\left(\mathrm{RMF}_{\mathrm{n}-1}-\mathrm{RMF}_{\mathrm{n}}\right)-\left(\mathrm{RMD}_{\mathrm{n}+1}-\mathrm{RMD}_{\mathrm{n}}\right)$

If this value is negative, we have a net fertility decline. The more this value decreases, the greater the net fertility decline is.

For measuring infant/child mortality, the five-year mean of all deaths $<5$ (including stillbirths) was computed for each year.

Because $\mathrm{NMF}_{\mathrm{d}}$ gives annual differences, the line can be very noisy. Two examples should illustrate this for Vienna and for Inner Carniola (see Graphs 4 and 4a). Nevertheless, we can see very clearly that, in Vienna, a persistent net fertility decline started in the very late 1890s, and was shortly interrupted in 1905/1906. We can observe a very slight net decline in Inner Carniola since the very late 1890s also, but with a striking variance and without persistency: in 1905 the decline turned around; unfortunately we cannot define, what extraordinary happened in 1905.

Infant mortality was significantly lower in Inner Carniola than in Vienna until about 1900. In Inner Carniola, breastfeeding was widespread, whereas in Vienna, the process of medicalization lowered infant/child mortality until about 1900. Thus in the end of the period the natural advantages associated with breastfeeding were no match for the advantages associated with having access to modern medicine. 
Graph 4: Net marital fertility decline $\left(\mathrm{NMF}_{\mathrm{d}}\right)$ in Vienna

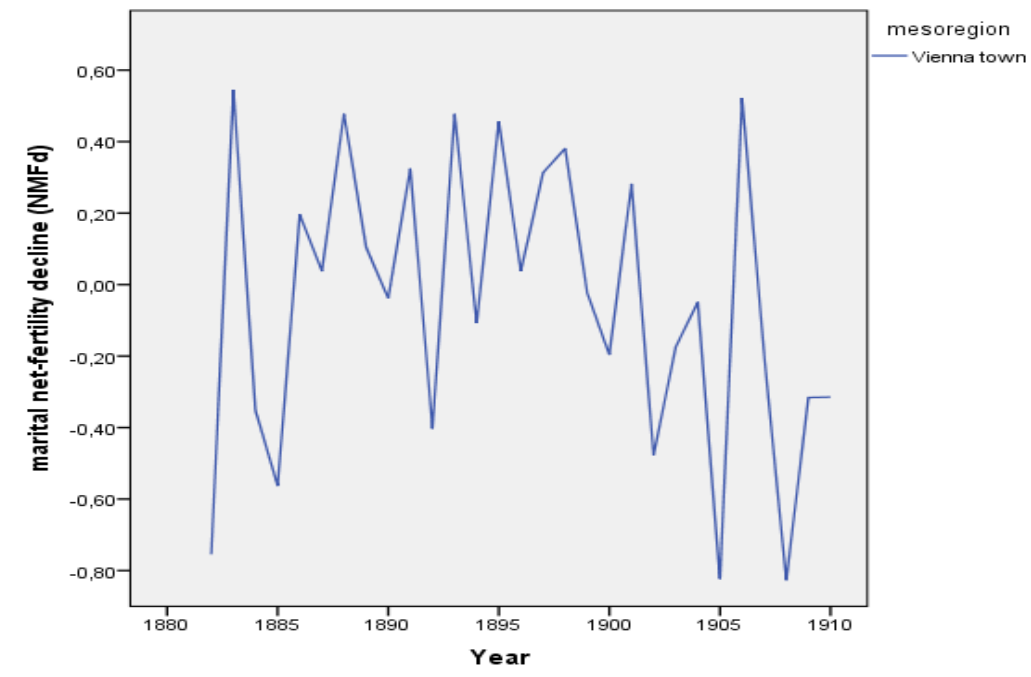

Graph 4a: Net marital fertility decline $\left(\mathrm{NMF}_{\mathrm{d}}\right)$ in Inner Carniola

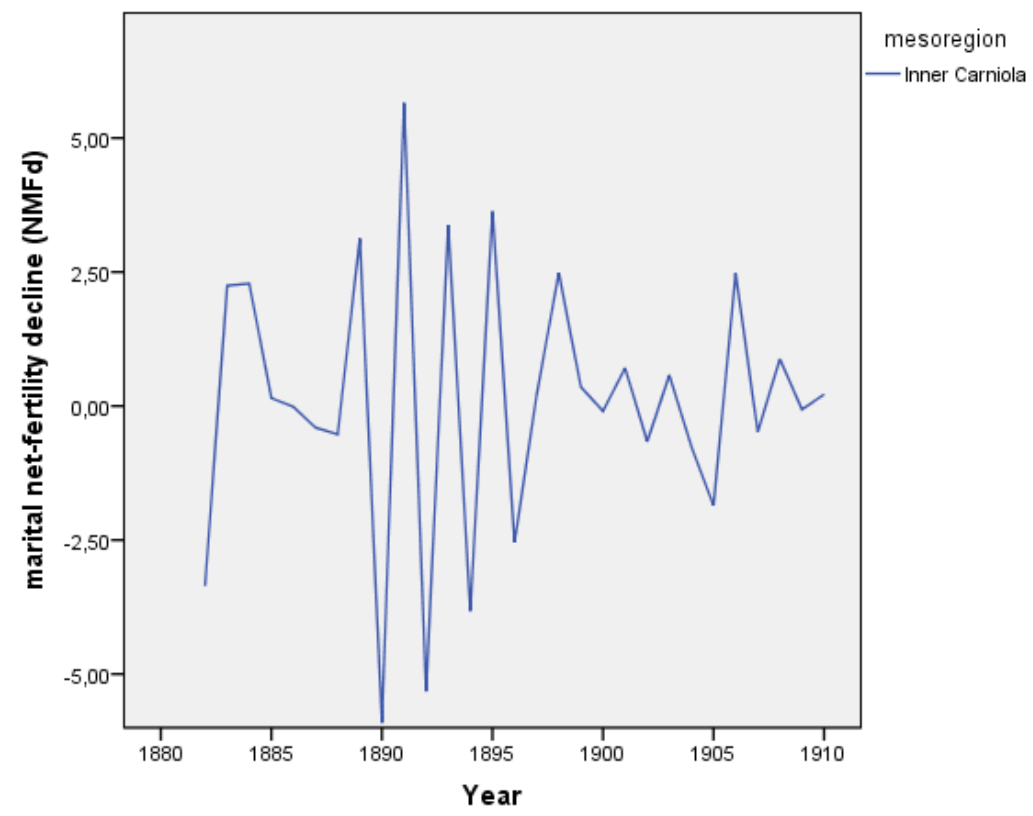

The high variance of the line in Graph 4a is a reminder, mentioned earlier in this paper, that there are concerns regarding the quality of the data in the more southern countries of the area under research. Obviously, we have to reject this assumption using another measure to differentiate net fertility decline, which can be derived from the NMF $\left(\mathrm{NMF}_{\mathrm{dd}}\right)$ :

$\mathrm{NMF}_{\mathrm{dd}}=\left(\mathrm{RMD}_{\mathrm{n}-1}-\mathrm{RMD}_{\mathrm{n}}\right)+\mathrm{RMF}_{\mathrm{n}-1}$

$\mathrm{NMF}_{\mathrm{dd}}$ gives us a line, comparable directly to the RMF. To the extent that the RMF is lower than $\mathrm{NMF}_{\mathrm{dd}}$ and decreasing, we have to state a net fertility decline (see Graphs 5 and $5 a)$. 
Graph 5: Net marital fertility decline $\left(\mathrm{NMF}_{\mathrm{dd}}\right)$ in Vienna

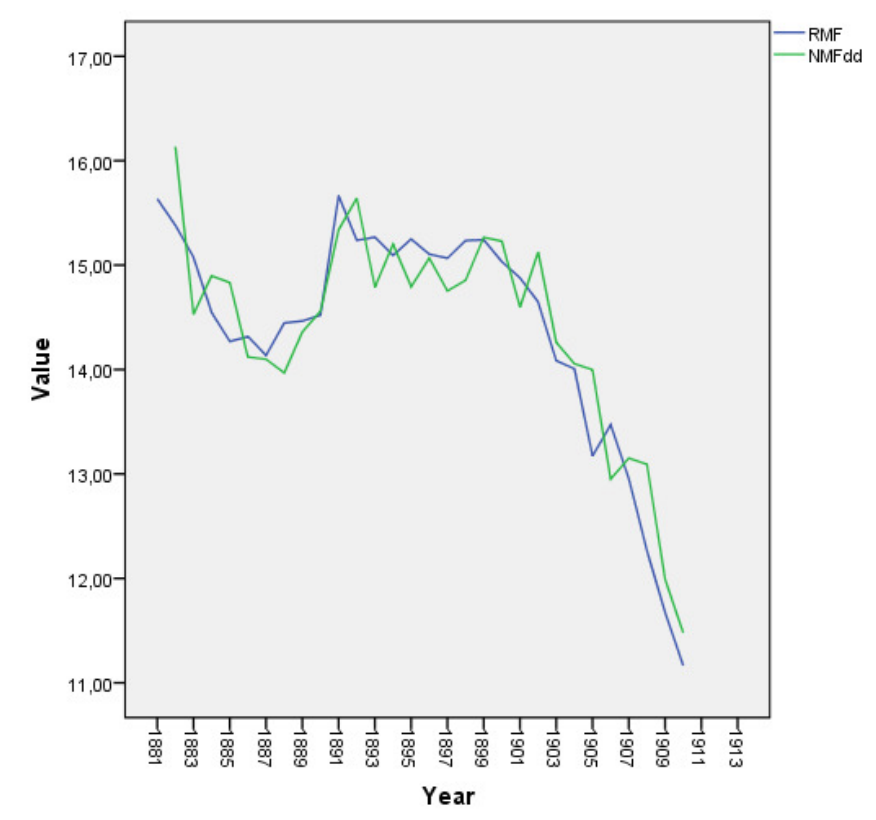

Graph 5a: Net marital fertility decline $\left(\mathrm{NMF}_{\mathrm{dd}}\right)$ in Inner Carniola

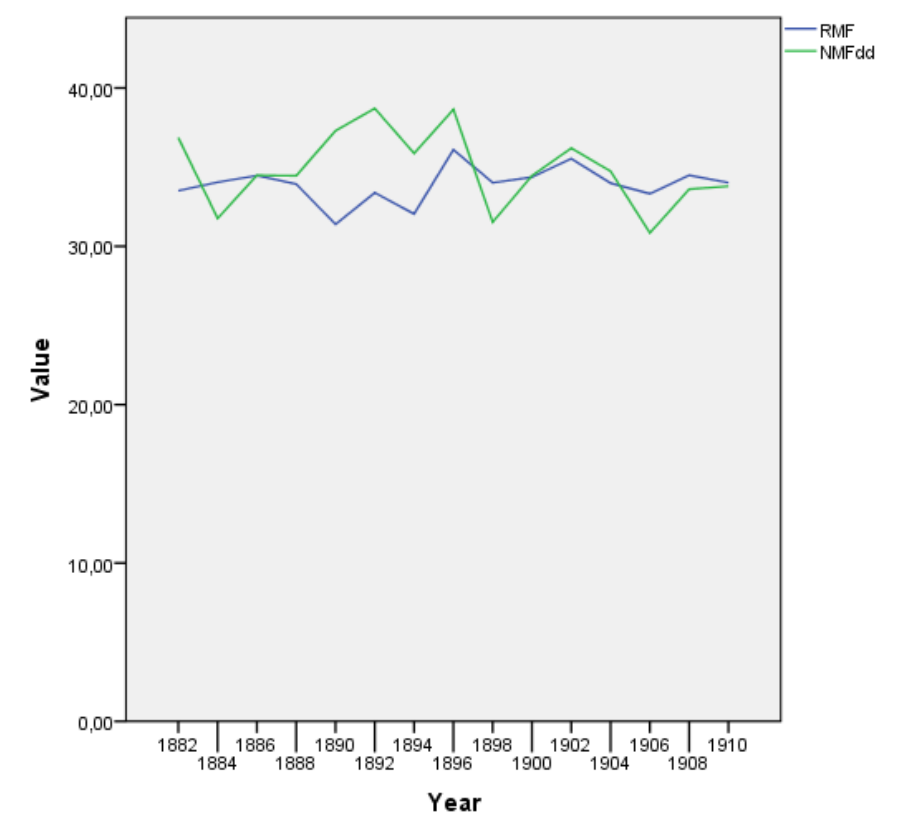

For both meso-regions, we can detect a strong connection between marital fertility and infant/child mortality. The latter is simply much more noisy for Carniola. This is an indicator of the dependence on good years, and on the deficits or delays in medical care in Carniola. The opposite was the case in Vienna, and more generally in the German-speaking northern countries of the area under research. Breastfeeding could help to protect against infant mortality $(<1)$, but it could not prevent child mortality $(1$ to $<5)$. Whereas in Vienna we see a significant and persistent net fertility decline ( RMF is lower than $\mathrm{NMF}_{\mathrm{dd}}$ ) since about 1902 , no net fertility decline as a persistent process is observable in Inner Carniola, with the two lines crossing permanently. 
However, we can also see that, in the last decade up to 1910, the RMF as well as the $\mathrm{NMF}_{\mathrm{dd}}$ become a little less noisy, which indicates the entry into a more modern era of declines in fertility and child mortality. The strong relationship between RMF and $\mathrm{NMF}_{\mathrm{dd}}$, which is observable in Carniola, also speaks for the quality of data, as the higher variance corresponded with empirical reality due to a lack of development.

The high variance and noise in annual marital fertility are not necessarily caused by worse data quality, but may be the result of temporary out-migration. As was already mentioned, many of the very small farmers in Carniola temporarily left home to earn money as tradesmen or peddlers. Normally, they left their farms during the winter, but obviously they were sometimes away for one or even two years. This phenomenon naturally had an impact on the sex ratio (the number of females per 100 males, 14 to 60 years old) and on fertility. In Tschernembl (Črnomelj, Inner Carniola), for example, the mean sex ratio was 150 , the mean marital fertility was 291 , and the correlation of sex ratio and marital fertility was $-.765^{* *}$ (very significant) between 1871 and 1913. In Leibnitz, a district in Southern Styria (small tillers), the correlation was only .130 , which is not significant, the mean sex ratio was 102 , and the mean marital fertility was 265. The agrarian district of Leibnitz experienced a low level of permanent out-migration to the nearby capital of Graz, but this migration obviously was not gendered, unlike the temporary out-migration from Tschernembl/ Črnomelj and other areas of Carniola. Generally, with the exception of Vienna, we can find no net fertility decline until the eve of World War I, not even in the other, much smaller cities, in the industrial regions, or among the smallholders, among whom a marked gross decline is observed.

\subsection{Non-marital fertility and its changes}

To a certain degree, non-marital fertility (the number of out-of-wedlock children born per 1,000 unmarried, women of fertile ages) is the mirror of marital fertility (number of non-marital children born per 1,000 married women of fertile ages), but it depends on the transition process. There is a high and — not surprisingly-negative correlation in the $1870 \mathrm{~s}$, but it is lowered later (s. Table 6) because in many high-fertility districts, fertility did not decline and non-marital fertility remained low or even decreased. On the other hand, in many districts the earlier higher fertility was regressing along with non-marital fertility. Thus, some crossed lines appear, with the correlation changing in height, but not in general direction. Generally, non-marital 
fertility was declining nearly everywhere, but not due to the woman's decision to have fewer illegitimate children. Thus we cannot speak of a transition process.

Table 6: Correlation between marital and non-marital fertility (about 100 districts)

\begin{tabular}{|l|l|}
\hline Year & Spearman's corr. \\
\hline 1871 & -.701 \\
\hline 1880 & -.641 \\
\hline 1890 & -.760 \\
\hline 1900 & -.738 \\
\hline 1910 & -.616 \\
\hline
\end{tabular}

Moreover, nuptiality was increasing. In the core regions of conservative, agrarian niche systems (the Carinthia Midlands and agarian Upper Styria) marital fertility and nuptiality grew markedly, as part of a catch-up process, and non-marital fertility also increased slightly. Illegitimacy still was an option for those who wanted to have children without being married in these regions. Non-marital children faced some symbolic discrimination, but in the end they were accepted as part of the needed workforce. The landowning farmers obviously knew that, on their own, they would never be able to reproduce the workforce needed in their non-mechanized economy, which involved dealing with heavy livestock and forests, especially given the outmigration of farmhands to work in the industries.

The highest and even increasing values in Table 7 can be found in the abovementioned agrarian niche systems, in contrast to a strong increase in nuptiality (see Table 1). In the industrial region of Upper Styria, we also find many agrarians belonging to this system, as well as a fluctuating mass of industrial workers who stayed unmarried and produced illegitimate children. In the big towns (Vienna) with a pronounced third sector, we know there was high out-of-wedlock fertility among the female house servants, apprentices, etc. On the other hand, non-marital fertility declined very strongly. Due to the fact that, in Hapsburg Austria, no marriage was legitimate without a church wedding, we can assume that many industrial workers or people living in the big towns did not marry, but instead lived in partnerships. The aggregate data used here cannot give a definitive answer to this question. Non-marital fertility was lowest in more egalitarian nuptiality systems, and usually occurred among the poor, such as smallholders (Wine Quarter); and was by far the lowest among the non-German-speaking people in the south. Again, we find that this 
"ethnicization" of patterns is primarily connected to social issues, such as poverty. On the other hand, there are strong hints that abortions and cases of infanticide were even more frequent in the areas with a low rate of non-marital fertility (Kurmanowytsch 2002): the factor of shame was more pronounced there, because in general there was no social barrier for young people to marry.

Table 7: Non-marital fertility and illegitimacy rates (percentages of out-of-wedlock births) in selected meso-regions

\begin{tabular}{|c|c|c|c|c|}
\hline MERL & $\begin{array}{l}1871- \\
1880\end{array}$ & $\begin{array}{l}1881- \\
1890\end{array}$ & $\begin{array}{l}1891- \\
1900\end{array}$ & $\begin{array}{l}1901- \\
1910\end{array}$ \\
\hline $\begin{array}{c}\text { Vienna non-marital fertility } \\
\text { Illegitimacy rate }\end{array}$ & $\begin{array}{l}104,9 \\
46,4\end{array}$ & $\begin{array}{l}91,0 \\
42,8\end{array}$ & $\begin{array}{l}69,0 \\
34,3\end{array}$ & $\begin{array}{l}51,3 \\
30,4\end{array}$ \\
\hline Wine Quarter (Lower Austria) & $\begin{array}{l}35,6 \\
11,2\end{array}$ & $\begin{array}{l}34,9 \\
10,9\end{array}$ & $\begin{array}{l}33,0 \\
11,2\end{array}$ & $\begin{array}{l}30,1 \\
11,0\end{array}$ \\
\hline Industrial Upper Styria & $\begin{array}{l}106,7 \\
47,0\end{array}$ & $\begin{array}{l}103,5 \\
43,2\end{array}$ & $\begin{array}{l}97,6 \\
38,2\end{array}$ & $\begin{array}{l}95,0 \\
35,0\end{array}$ \\
\hline Agrarian Upper Styria & $\begin{array}{l}78,3 \\
45,0\end{array}$ & $\begin{array}{l}89,0 \\
47,4\end{array}$ & $\begin{array}{l}88,3 \\
43,5\end{array}$ & $\begin{array}{l}90,2 \\
41,4\end{array}$ \\
\hline Carinthia Midlands & $\begin{array}{l}\mathbf{9 2 , 9} \\
\mathbf{5 0 , 7}\end{array}$ & $\begin{array}{l}97,4 \\
49,8\end{array}$ & $\begin{array}{l}96,1 \\
46,1\end{array}$ & $\begin{array}{l}101,4 \\
43,7\end{array}$ \\
\hline Southern Styria & $\begin{array}{l}40,7 \\
20,7\end{array}$ & $\begin{array}{l}40,3 \\
19,9\end{array}$ & $\begin{array}{l}38,0 \\
19,0\end{array}$ & $\begin{array}{l}34,3 \\
17,5\end{array}$ \\
\hline Lower Styria & $\begin{array}{l}39,9 \\
17,2\end{array}$ & $\begin{array}{l}35,0 \\
14,3\end{array}$ & $\begin{array}{l}29,5 \\
11,6\end{array}$ & $\begin{array}{l}26,9 \\
10,4\end{array}$ \\
\hline Inner Carniola & $\begin{array}{l}16,4 \\
5,3\end{array}$ & $\begin{array}{l}12,9 \\
3,8\end{array}$ & $\begin{array}{l}11,4 \\
3,2\end{array}$ & $\begin{array}{l}9,9 \\
2,8\end{array}$ \\
\hline Trieste & $\begin{array}{l}49,0 \\
18,9\end{array}$ & $\begin{array}{l}42,6 \\
17,7\end{array}$ & $\begin{array}{l}38,0 \\
17,6\end{array}$ & $\begin{array}{l}40,3 \\
17,5\end{array}$ \\
\hline Istria Islands & $\begin{array}{l}5,3 \\
1,6\end{array}$ & $\begin{array}{l}6,5 \\
2,0\end{array}$ & $\begin{array}{l}5,5 \\
1,9\end{array}$ & $\begin{array}{l}5,3 \\
2,0\end{array}$ \\
\hline
\end{tabular}

Bold: regions with a catch-up process; italics: non-German-speaking areas

Marital fertility is only slightly connected to the dominance of large farms with heavy livestock that represented niche systems. Spearman's coefficient (marital fertility and heavy livestock unit per farm) amounts to just -.244*. This effect appears because 
there are many districts with a low number of units, but which have different rates marital fertility, with some showing higher values and nearly no decline (conservative systems), and others showing lower values and a strong decline (smallholders). Finally, the core regions with traditional niche systems might have also seen an increase in marital fertility as a result of a social catch-up process. Thus, there were some crossed lines. The coefficient of heavy livestock unit per farm with non-marital fertility was, however, .601**. Non-marital fertility was much more unambiguously distributed than marital fertility. We can definitely assume that, because at that time, cattle was more expensive than grain, the farmers raising heavy cattle were richer; and that the niche system and socially established barriers to marriage were connected to wealth; while a high rate of non-marital fertility in these regions was associated with the poor and the landless. In the more egalitarian marriage systems, (smallholders and small farmers mainly in the non-German-speaking south), non-marital fertility was low, and was also associated with poverty, but with the common poverty of both landowners and tenants.

In the 1900 census, a new occupational scheme was introduced that allows us to distinguish for the very first time between "workers" (=servants) and "helping hands" in agriculture. Until these times, we can expect to find that, in the conservative, hierarchical agrarian systems in the north, relatives and even the children of the farmer were listed among the "workers," and that the farmers' wives were counted among the relatives without their own profession. In the agrarian south, relatives were usually counted together with the relatives without a profession. However, in 1910 in, for example, Istria, the farmers' wives were often registered as relatives without their own profession, again disregarding the rule. Thus, we can find discriminatory tendencies of one kind or another everywhere.

In 1900 in agrarian Upper Styria (a conservative, non-egalitarian marriage system engaged in cattle raising with many celibate farmhands) $43 \%$ of the "workers" (farmhands) and $73 \%$ of the "helping hands" were females (including the farmers' wives), and the proportion of "workers" to "helping hands" was 1.8:1. On the Istria islands, by contrast, $21 \%$ of the "workers" and $81 \%$ of the "helping hands" were females, and the proportion of "workers" to "helping hands" was 0.2:1. These numbers are representative of the very different social systems in the regional agrarian societies. The servant system was largely associated with cattle raising, as well as with a much higher percentage of celibate women and illegitimate births (Mitterauer 1983, 1986, and 1995); the Spearman coefficient between the heavy livestock unit and 
the percentage of married women aged 14-44, was $-.496^{* *}$ in 1900 , and the coefficient between heavy livestock unit and out-of-wedlock fertility was .629**, disregarding the cities.

Regarding Table 7 it should be pointed out that the illegitimacy rates can be misleading when measuring out-of-wedlock fertility, especially when there are large gaps between marital fertility and non-marital fertility. If, for example, marital fertility decreases strongly and non-marital fertility remains stable, the illegitimacy rate would increase only due to the decrease in marital fertility, without being connected to an (non-existent) increase in non-marital fertility.

Table 8 shows the impact of the heavy livestock unit on basic nuptiality and fertility issues. The industrial Upper Styria region, where less than $50 \%$ of employed people were working in agriculture, also included large agrarian areas; thus, non-marital fertility among industrial workers and among workers engaged in the agrarian niche system of cattle-raising were mixed up to a certain extent.

Table 8

\begin{tabular}{|l|l|l|l|l|}
\hline Meso-regions & HLU & WFratio & Fmarried, 20-44 & NMF \\
\hline Vienna & 5,6 & 5,6 & 47,1 & 61,6 \\
\hline Wine Quarter (Lower Austria) & 4,0 & 0,4 & 55,8 & 31,0 \\
\hline Industrial Upper Styria & $\mathbf{1 6 , 0}$ & $\mathbf{2 , 1}$ & $\mathbf{4 7 , 6}$ & $\mathbf{9 6 , 0}$ \\
\hline Agrarian Upper Styria & $\mathbf{1 3 , 0}$ & $\mathbf{1 , 9}$ & $\mathbf{4 0 , 0}$ & $\mathbf{8 6 , 7}$ \\
\hline Carinthia Midlands & $\mathbf{1 2 , 1}$ & $\mathbf{1 , 4}$ & $\mathbf{4 1 , 1}$ & $\mathbf{7 3 , 1}$ \\
\hline Southern Styria & 5,5 & 0,4 & 44,9 & 35,2 \\
\hline Lower Styria & 4,1 & 0,3 & 51,2 & 27,9 \\
\hline Inner Carniola & 4,7 & 0,4 & 59,6 & 10,3 \\
\hline Trieste & 3,2 & 0,3 & 50,8 & 37,3 \\
\hline Istria Islands & 3,5 & 0,2 & 58,5 & 4,9 \\
\hline
\end{tabular}

Bold: regions with a catch-up process; italics: non-German-speaking areas; HLU=heavy livestock unit; Fmarried, 20-44= percentage of married women among all women aged 20-44; NMF=non-marital fertility per 1,000 non-married women, 14-44 years old; WFratio=workers per helping hands $(=1)$

The difference between the German-speaking region of Southern Styria and the Slovenian-speaking, adjacent region of Lower Styria in NMF and Fmarried,20-44 shows that the agricultural ecotype was not the only important socioeconomic factor; but, rather, that there was also a socio-cultural factor coupled with ethnicity. It makes 
no sense to compute factor loadings referring to that issue, as doing so would be very artificial. Yet we should consider the possibility that socioeconomic and cultural patterns can change, but that ethnicity mostly stays the same.

\subsection{Births and Seasonality}

The numbers of marriages (s. chapter 3.2) showed a traditional seasonal pattern with significant peaks, in November and February especially and less pronounced in May. Births obviously also followed a traditional, but different pattern, showing the highest amounts in the early beginning and a more or less trendy decrease as the year progresses. Graph 6 proves this pattern for very different systems (regions), namely agrarian, industrial and urban ones, different agrarian ecotypes (heavy-livestock, small tillers, mediterranean agrarians) and social nuptiality systems (egalitarian and non-egalitarian). There are variations of course, but the common trend is: the closer the summer, the lower the numbers of births.

Five main theories are addressing canonical rules, agricultural seasons, the seasonality of marriages (Pfister 1994, Ehmer 2004), geography and climate issues (Doblhammer and Rodgers and Rau 2000) and finally migration (Quaranta 2011). Additional reasons for special patterns of seasonal birthing perhaps could be found in physicalbiological, psychological and mental fields also. Canonical rules forbid intercourse in the last 40 days before Christmas and Easter, but obviously were not obeyed. The proposal to use a biological period of 9 months since the marriage to explain seasonal patterns of birthing is too fuzzy, we cannot assume conception following immediately. On the other hand various examples from local studies do prove that premarital conception was anything but rare (Pfister 1994, Ehmer 2004).

In Wald parish (agrarian Upper Styria) for example we can count 31 marriages between 1880 and 1910, where the bride gave a birth in the next 12 months after marriage, and 18 out of these brides gave a birth less than eight months after. Thus $58 \%$ of these births obviously had been premaritally concepted. Among those who were pregant as brides the average distance to the first following birth ranged from 10 to 12 months. The city of Vienna shows the most striking deviation from the seasonal birthing pattern. In this urban area we easily can detect, that the less frequented marriage months of December and January - along the traditional pattern - lead to a lack in births in the months of September and October. On the other hand we can find peaks of birthing in the months of November and December, stemming from the 
Graph 6: Seasonal birthing, monthly average percentages, 1881-1897

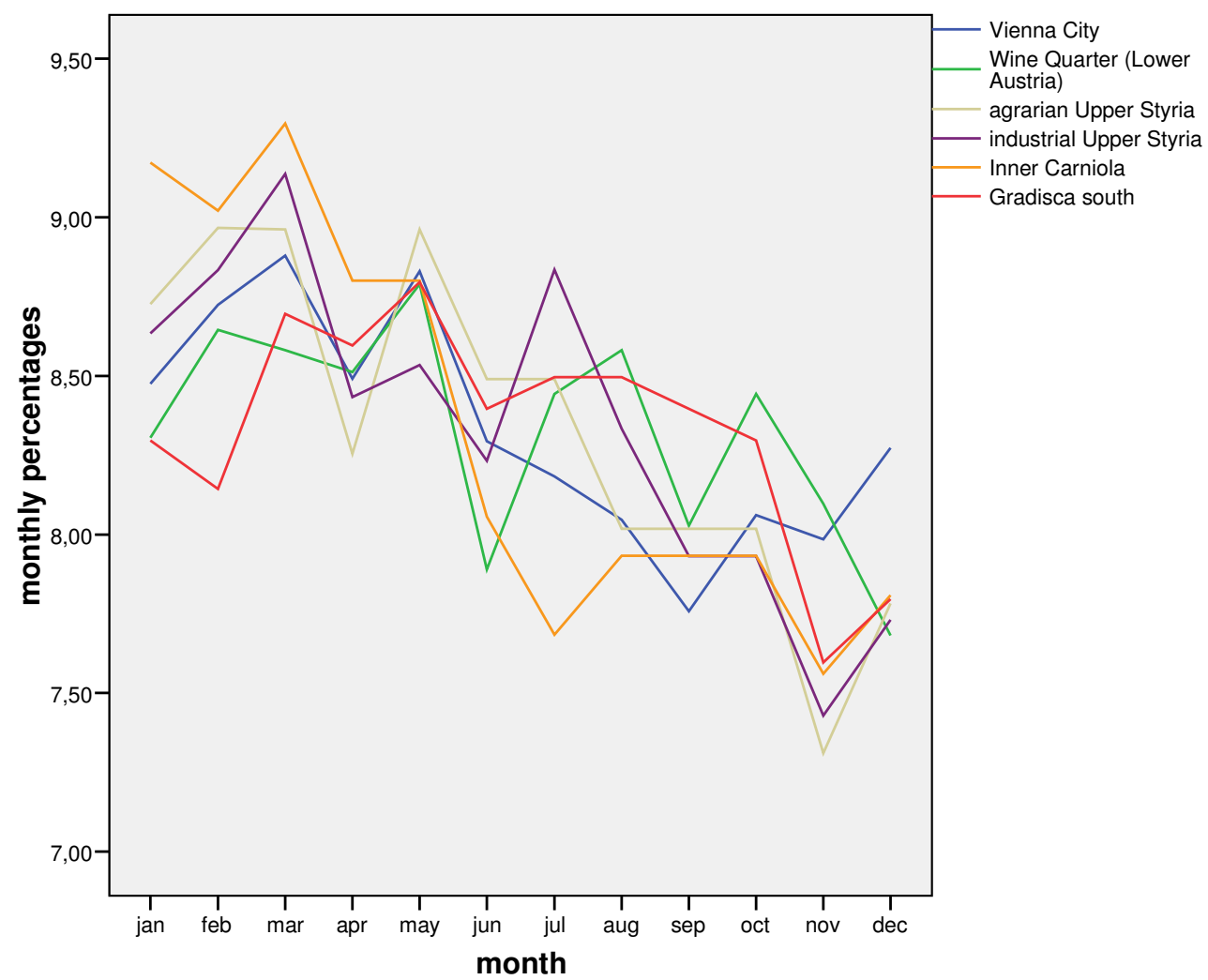

highly frequented marriage month of February, also following a traditional seasonal marriage pattern. Finally can be said, thesis addressing agricultural seasons fits best. Doblhammer and Rodgers and Rau (2000) have identified geography/climate and agricultural issues as most decisive factors. We guess, that geography and climate are indirect factors, leading us to the direct factor, namely the agrarian ecotype, which obviously influenced the decision on the seasonal timing of birthing strongly. Yet we cannot follow the argument of Doblhammer and Rodgers and Rau (2000) that in Austria (1881-1914) the February peaks in births are associated with "rebirth" of nature. The conception should have happened then in May last year, but a rebirth of nature in most of the areas could be experienced in March and April already and of course in summer times also. Quaranta (2011) stated, that in Italian alpine regions temporary migrants concentrated their births in the months from August to November. This effect obviously partly can be found in the deviating line of Inner Carniola, where temporary out-migration for peddling especially was widespread. Due to the fact, that a significant higher number of births were given during late winter and early spring, in February and March, it can be derived, that in these cases the women were less or even not hindered by their pregnany during the working season (April to October). We even can say, that these women, having given birth in January or February also were less hindered by their motherhood when the working season 
started again, because the baby was already one or two months old. That means, that the babies could have already survived the most critical first months, cause infant mortality was the highest during these first two months. That the peak in March was most pronounced in the agrarian Upper Styria region may have been caused by numerous non-marital births, given by farmhands (cf. Becker 1990). We can conclude, that the most frequent marriage months, namely November, February and, less pronounced, May have been mirrored only partially in the seasonal birthing 9-11 months later. The scheduling of births into the early months of the year, due to the duration of the agricultural working period from spring to autumn - partially dependent on the agrarian ecotype (graining, cattle-raising, wine growing) - obviously was the much stronger reason for the seasonality of birthing.

\section{Regional demographic patterns: Cluster analysis}

Cluster analysis is undoubtedly one of the most useful tools for performing regional analysis, identifying and differentiating between different regional systems, and discerning demographic behavior and structures and patterns. Yet Cluster analysis gives us information for a specific moment in time only. One of the main problems of clustering is, of course, that it is less useful in illustrating processes. In a preliminary step, we are using the mean values of different variables (see Table 9) covering the period from 1871 to 1913 , as indicators of a time series (see Figure 3). There is no definitive answer to the question of how many clusters we need to describe regional patterns, because in the end each single unit can appear as its own cluster. Answering this question based on a distinctive skip in the distance from one agglomeration step to the next is easy (elbow criterion, Bacher and Pöge and Wenzig 2010), but it is difficult to decide on a useful minimum of clusters. Pragmatic, structural arguments based on the regional data combined with results in a similarity, a dissimilarity matrix, and a careful observation of the changes in memberships when using different numbers of clusters, can help. Generally, we expected to find that we would need a minimum of seven clusters, representing different systems, namely:

- urban sites,

- industrial sites,

- agrarian ecotypes with heavy livestock,

- agrarian ecotypes with small tillers and smallholders, and

- three ethnicities (Germans, Slovenes or Croats, Italians) 
Fig. 3: Regional Clustering, 1900

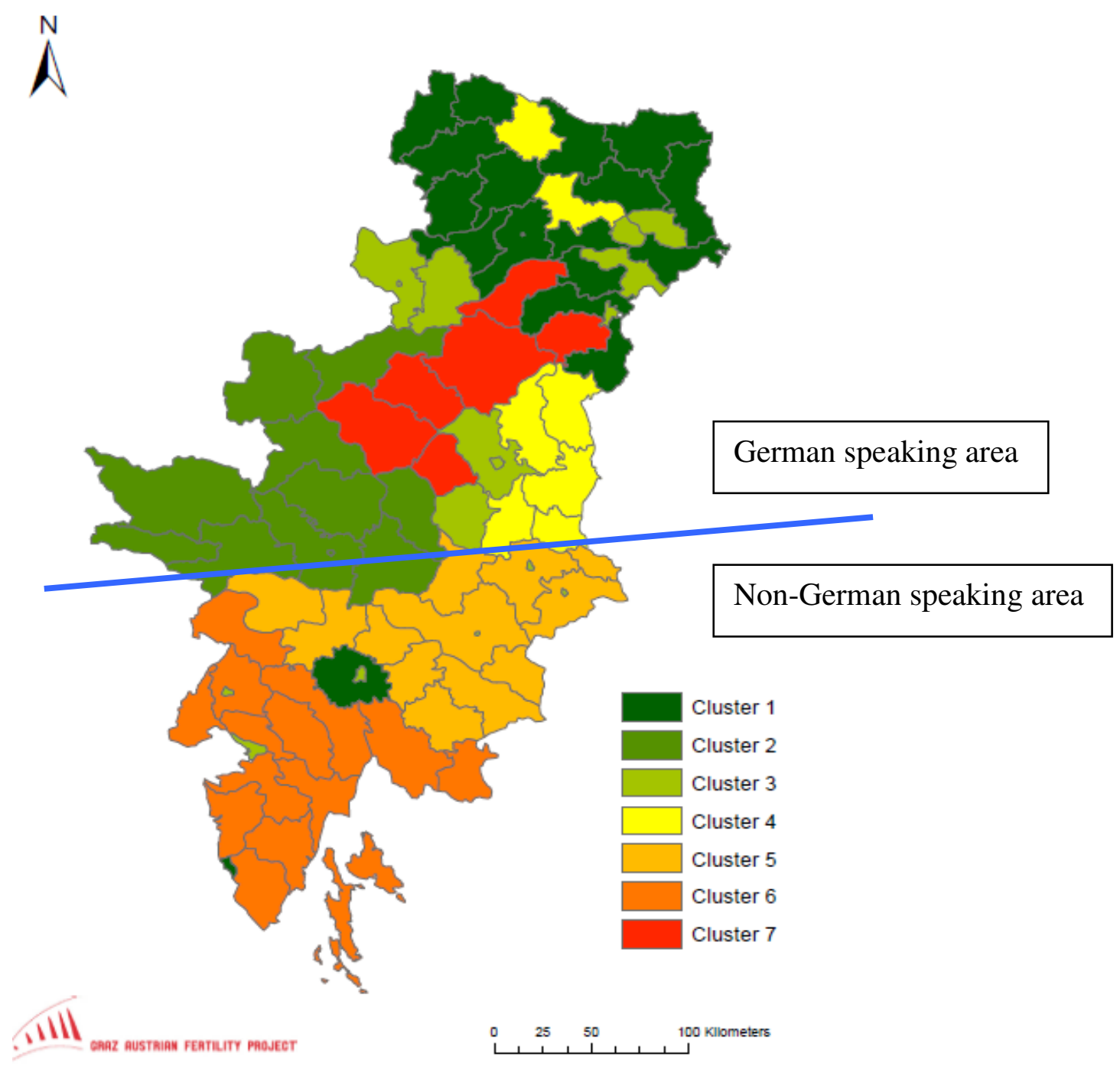

A cluster analysis should be performed with certain assumed numbers of clusters plus/minus two or three clusters. In our case, we tried solutions ranging from five to 10 clusters, expecting to find that seven clusters was the best solution (Ward method, z-standardization). In the end, a six-cluster solution fitted best, as there were high values for homogeneity within the clusters and high values of dissimilarity between the clusters. However, we decided to stay with seven clusters. First, we accepted the fine difference between the Slovenes in Lower Styria and the other Slovenes (and Croats) in Carniola and Istria, plus the Italians in Gorizia and Istria (Cluster 5, Cluster 6). Second, we found it sensible to differentiate between the German-speaking small tillers (Cluster 3, Cluster 4, partially Cluster 1 also) and the small tillers from the nonGerman south (Cluster 5, Cluster 6). 
Table 9: Regional clustering: cluster structures (mean 1871/80 $1910 / 13)$

\begin{tabular}{|c|c|c|c|c|c|c|c|}
\hline \multirow[t]{2}{*}{ Cluster } & $\begin{array}{l}\text { general } \\
\text { fertility }\end{array}$ & $\begin{array}{l}\text { marital } \\
\text { fertility }\end{array}$ & $\begin{array}{c}\text { non-marital } \\
\text { fertility }\end{array}$ & $\begin{array}{l}\text { women } \\
\text { married } \\
24-44 \text { old } \\
\end{array}$ & $\begin{array}{c}\text { women } \\
\text { age at } \\
\text { marriage } \\
\text { (median) }\end{array}$ & $\begin{array}{c}\text { marital } \\
\text { infant } \\
\text { mortality } \\
(<1)\end{array}$ & $\begin{array}{c}\text { non-marital } \\
\text { infant } \\
\text { mortality } \\
(<1)\end{array}$ \\
\hline & Mean & Mean & Mean & Mean & Mean & Mean & Mean \\
\hline $\begin{array}{c}1 \\
(\mathrm{~N}=18)\end{array}$ & 153,64 & 292,17 & 37,39 & 71,74 & 25,73 & 26,36 & 48,41 \\
\hline $\begin{array}{c}2 \\
(N=11)\end{array}$ & 136,11 & 250,43 & 88,11 & 47,30 & 26,95 & 21,18 & 26,35 \\
\hline $\begin{array}{c}3 \\
(N=16)\end{array}$ & 115,31 & 222,18 & 46,17 & 59,76 & 26,02 & 22,56 & 30,60 \\
\hline $\begin{array}{r}4 \\
(N=7)\end{array}$ & 125,91 & 279,12 & 33,84 & 58,74 & 26,88 & 24,79 & 54,73 \\
\hline $\begin{array}{c}5 \\
(\mathrm{~N}=12)\end{array}$ & 146,41 & 324,79 & 26,55 & 64,10 & 25,38 & 18,96 & 27,29 \\
\hline $\begin{array}{c}6 \\
(N=16)\end{array}$ & 169,42 & 328,22 & 12,57 & 81,01 & 22,72 & 19,69 & 29,20 \\
\hline $\begin{array}{r}7 \\
(\mathrm{~N}=7)\end{array}$ & 148,58 & 239,95 & 85,66 & 63,43 & 26,38 & 22,29 & 29,52 \\
\hline
\end{tabular}

In spite of the clear and plausible results Figure 3 and Table 9 have delivered, it is important to keep in mind that the mean of the time series used in this cluster analysis can be misleading. We end up with a very similar mean by using two different series, with one starting the transition earlier, but having higher values at earlier times; and the other starting later, but having lower values at earlier times.

One way to consider serial data and processes in a cluster analysis is to cluster each year by each district and each variable selected in a first step, thus creating a membership table for each year by each district and each variable. In this step, a horizontal matrix is used, depicting each district with all its data years as cases below each other, and the indicators as variables. Finally, each district can appear with a certain number of years in a special cluster. Multiple memberships are therefore possible, resulting in a table of cluster loadings. Using this approach offers two benefits relative to using a traditional cluster analysis:

- we can include the time-series effect into the analysis, and

- we get a much more sensible cluster-membership table. 
Table 10: A multiple cluster-membership table of selected districts and cluster loadings in seven required clusters

\begin{tabular}{|l|l|l|l|l|l|l|l|}
\hline District & Cl_1 & Cl_2 & Cl_3 & CL_4 & Cl_5 & Cl_6 & Cl_7 \\
\hline Adelsberg/Postojna & $100 \%$ & & & & & & \\
\hline Bruck upon Mur & & $68 \%$ & $4 \%$ & & & $28 \%$ & \\
\hline Murau & & $32 \%$ & & $68 \%$ & & & \\
\hline Gradisca/Gorizia & $100 \%$ & & & & & & \\
\hline Klagenfurt town & $8 \%$ & $28 \%$ & & & $64 \%$ & & \\
\hline Lussin/Lušin & $24 \%$ & $36 \%$ & & & $28 \%$ & & $12 \%$ \\
\hline
\end{tabular}

When looking at all of the districts (about 100), it becomes clear that having seven required clusters provides a good approximation for a maximum number of clusters needed to depict different systems. In Cluster 7, only three districts are loading, with $12 \%$ at a maximum. The amount of five clusters would have been the minimum because one district loads with a major value in this cluster. This is not a definitive argument for a certain number of clusters, but rather an assertion that this number represents a good approximation. When the number of districts loading in a cluster becomes rare and the loadings become low, we can decide to skip this cluster.

Later on, we will simplify this table by classifying the districts along their loadings. We propose creating four classes:

- centered loading: districts have a loading of $80 \%$ to $100 \%$ in one cluster;

- absolute major loading: districts have a loading of $60 \%$ to $79 \%$ in one cluster;

- relative major loading: districts have a relative majority in one cluster (maximal loading should be more than $10 \%$ higher than that in the next-lower loaded cluster); and

- parted loading: the district is loading in two clusters with similar values, or in more clusters without a relative majority.

The whole cluster-membership table (containing 98 districts) covers 54 centered districts (55.1\% of all districts), 24 districts with an absolute major loading (24.5\% of all districts), six districts with a relative major loading (6.1\% of all districts), and 14 districts with parted loadings (14.3\% of all districts) only.

In Table 11 we can see that centered districts are reduced to two clusters only, and that a large number of districts have an absolute majority of loadings in these two 
clusters. Thus, two clusters (less than one-third of the optional clusters) comprise 74 districts in sum, or two-thirds of all districts.

Table 11: Distribution of memberships and loadings

\begin{tabular}{|l|l|l|l|l|l|}
\hline Cluster & centered & Abs. majority & rel. majority & Parted* \\
\hline & Number of districts & 1 & 1 & 4 \\
\hline Cluster 1 & 23 & 7 & 5 & 13 \\
\hline Cluster 2 & 29 & 15 & & 6 \\
\hline Cluster 3 & 2 & & & 3 \\
\hline Cluster 4 & & 1 & & 2 \\
\hline Cluster 5 & & 1 & & 5 \\
\hline Cluster 6 & & & & 3 \\
\hline Cluster 7 & & & & \multicolumn{3}{l|}{} \\
\hline
\end{tabular}

*Loadings in more clusters; for example, 29 districts have a centered loading (are centered) in

Cluster 2, and five districts have a parted loading in Cluster 6.

For example, there is no district loading in Cluster 3 with an absolute or relative majority. Five clusters are sufficient to cover the main regional patterns. Clusters 6 and 7 are represented by very small, third- and fourth-ranked loadings in parted districts only.

Cluster 1 could be called the "either low or mostly higher marital fertility cluster without decline," and Cluster 2 could be named the "either high or mostly lower marital fertility cluster with a gross decline." The regional partition primarily followed marital fertility. This result appears because the other variables, namely nonmarital fertility and infant/child mortality $(<5)$, regionally are more or less strongly correlated with marital fertility: the higher the marital fertility, the lower the nonmarital fertility; and the higher the marital fertility, the lower the infant/child mortality. The correlation was not linear when computed over all the districts. A few districts in Lower Austria, especially districts dominated by small farmers and smallholders (Wine Quarter, Forest Quarter), distorted the coefficients by having higher marital fertility and higher infant/child mortality until the 1890s. However, marital fertility was the highest and non-marital fertility the lowest in the southern, non-German-speaking regions, where infant/child mortality was the lowest until about 1900 due to widespread breastfeeding. In between, in large parts of Styria and Carinthia, marital fertility was low due to the predominance of conservative, agrarian 
regimes, and infant/child mortality and illegitimacy were high. These regions needed out-of-wedlock births to reproduce the workforce required in a non-mechanized, cattle-raising system of agriculture, especially when they also had significant levels of out-migration. These characteristic features can be supplemented with the percentages of married women of fertile ages and with the mean female age at marriage. Celibacy was significantly lower in the high marital fertility cluster, and the age at marriage was also lower (see Table 9).

Marital fertility, the mean female age at marriage, the percentages of married women, and non-marital fertility appear to be directly and logically correlated.

Marital infant/child mortality obviously is not linearly connected to marital fertility. We would expect to find that having more children would be associated with lower chances for each child to survive, due to increasing capital dilution. ${ }^{9}$ However, breastfeeding was very popular in the non-German-speaking south, and we do not know why this was not the case in the more northern, German-speaking parts of the area under research. As was noted previously, child mortality did not regionally differ because breastfeeding cannot prevent death between 1-5 years old children.

Since in this serial clustering each district is depicted for each year with a cluster membership, the series of these values represent the different ways in which regions entered into the transition, whether early or delayed, weakly or strongly, persistently or turbulently, etc. The more widely spread the loadings of a region are, and the more clusters the region enters on its demographic path, the more turbulent the story is. If it is turbulent at a high level of fertility or during a strong decline, changing the strata permanently, we can recognize this by reading the different values of cluster membership in different years. This kind of serial clustering appears to be a potential tool.

A cluster membership in this serial cluster analysis does not, of course, only refer to a certain district, but also to a certain time. A Cluster X can comprise districts in a late period, such as 1905-1910. In this case, the same membership could mean low fertility in this period, reached after a decline. In the first step of the analysis, when each year and each district is assigned a membership for a certain cluster, the same cluster membership could match a district with low fertility at the beginning of the time series, while increasing later on.

\footnotetext{
${ }^{9}$ It is possible, however, that the helping hands of older siblings could have increased the chances of the younger surviving, cf. Vandezande and Mandemakers and Kok 2011.
} 
A second step is therefore necessary to address the process as a whole, determining trends. For that reason, the percentages of memberships, such as those in Table 10, are clustered. These percentages reflect the multiple memberships of each district throughout the whole period (1871-1910). Districts that did not exist over the whole period have been newly installed, divided, or abolished; they are not skipped, but instead appear with those years in which they existed. Table 12 shows the results of this analysis. Seven clusters were again chosen, based on different structural patterns and socioeconomic and ethnic/linguistic factors.

Table 12: Marital fertility trends (mean) in seven districts

\begin{tabular}{|l|l|l|l|l|l|}
\hline Cluster & District (Meso-region) & $\begin{array}{l}1871- \\
1880\end{array}$ & $\begin{array}{l}1881- \\
1890\end{array}$ & $\begin{array}{l}1891- \\
1900\end{array}$ & $\begin{array}{l}1901- \\
1910\end{array}$ \\
\hline \multirow{2}{*}{\begin{tabular}{l} 
Mean \\
\hline 2
\end{tabular}} & Adelsberg (Inner Carniola) & 348,2 & 360,2 & 357,8 & 368,9 \\
\hline 3 & Wolfsberg (Carinthia East) & 239,4 & 261,3 & 263,4 & 278,3 \\
\hline 3 & $\begin{array}{l}\text { Wr. Neustadt Surroundings } \\
\text { (Lower Austria, Industrial region) }\end{array}$ & 274,9 & 280,7 & 281,2 & 262,1 \\
\hline 4 & Murau (Agrian Upper Styria) & 252,7 & 246,1 & 253,5 & 264,2 \\
\hline 5 & Vienna & 214,0 & 203,4 & 197,0 & 165,5 \\
\hline 6 & $\begin{array}{l}\text { Mistelbach (Lower Austria, Wine } \\
\text { region) }\end{array}$ & 326,7 & 323,9 & 305,6 & 283,3 \\
\hline 7 & Leoben (Industrial Upper Styria) & 235,4 & 224,5 & 233,1 & 230,9 \\
\hline
\end{tabular}

Figure 4 is a map based on the results of this regional, serial analysis of the trends in fertility between 1869 and 1910. It does not greatly differ from the picture given by Figure 3 , but it do show the patterns of the process of marital fertility decline, and not only the structure of marital fertility in a given year or as a mean of many years.

Due to the fact that annual series have been clustered, each district is depicted, even when its series is not completed, due to administrative changes, such as the elimination of a district or the creation of a new one.

Table 12 and Figure 4 show significantly different systems, defined by their patterns of marital fertility decline between 1871 and 1910. The districts located in the nonGerman-speaking south (Carniola, Gorizia, and Istria) almost exclusively belong to Clusters 1 and 6, which indicates a very high degree of internal similarity. There are no districts in the German-speaking northern part of the area, which was included in 
Cluster 1, and has a high degree of external dissimilarity. Thus, Cluster 1 represents a peculiar fertility system that covers most of the non-German-speaking south.

Another unusual system was the urban one (Cluster 5), which covers not only the huge capital of Vienna, but also most of the medium-sized (Graz, Klagenfurt) and smaller cities (Cilli/Celje, Pettau/Ptuj, and Waidhofen upon Ybbs).

A third system was created by industrialized and semi-industrialized districts, most of which were situated in the Crown land of Styria and southeastern Lower Austria (Cluster 7). Many of these districts had remarkable percentages of the population occupied in the third sector also (trade, tourism). In these districts, we can also discern a catch-up process. The in-migrants mainly came from adjacent agrarian areas, and took the opportunity to marry and to establish their own households, which they had been unable to do as farmhands in the countryside. Thus, marital fertility rose sharply in the 1890s, but then began a steep decline starting around 1900, most likely due to changes in the cost-benefit relationship of having children, as well as the growing awareness of the quantity-quality tradeoff (Doepke 2005).

Clusters 2 and 4 are conservative agrarian systems with heavy-livestock, nonegalitarian nuptiality structures; these are niche systems with high percentages of celibate farmhands. They start the period with the lowest marital fertility, but in a catch-up process, marital fertility increases following a large number of new and young marriages, which indicates a weakening of traditional social structures in the countryside. The probability of being married by the end of a given year for a woman who was celibate at the end of the previous year increased from 0.022 in the 1870 s to 0.039 in the 1900s in agrarian Upper Styria, and from 0.024 to 0.039 in agrarian Carinthia. This process was indicated by an increase in marital fertility..Paradoxically, this increase was also generally found throughout the non-German-speaking south, but the reason for it was different: a more egalitarian nuptiality system and relatively low infant mortality furthered nuptiality. When a child is considered a basic good and infant mortality is relatively low, the survival costs are also low, which triggers stable or even increasing fertility (Doepke 2005).

Finally, Clusters 3 and 6 fit best with an agrarian structure made up of small grain farmers or even smallholders (winegrowers, fishermen, Cluster 6 predominantly). These structures covered the north of Lower Austria and the southeast of Styria, and therefore included the entire area of Lower Styria, which, since 1918, was part of Yugoslavia or Slovenia. These latter districts were settled by a huge majority of Slovenes, but obviously they shared the fertility behavior of adjacent German- 
speaking farmers more than that of the Slovenes in Carniola, the Italians in Gorizia, or the Croats in Istria. However, whereas the smallholders (Cluster 6 especially) started with very high fertility and then experienced a strong (gross) decline, the districts of to Cluster 3 (small grain farmers) had lower levels of fertility and saw a slight (gross) decline only. By the 1900s, the two regions had similar fertility levels.

Figure 4: Regional, serial cluster analysis, trends in marital fertility*

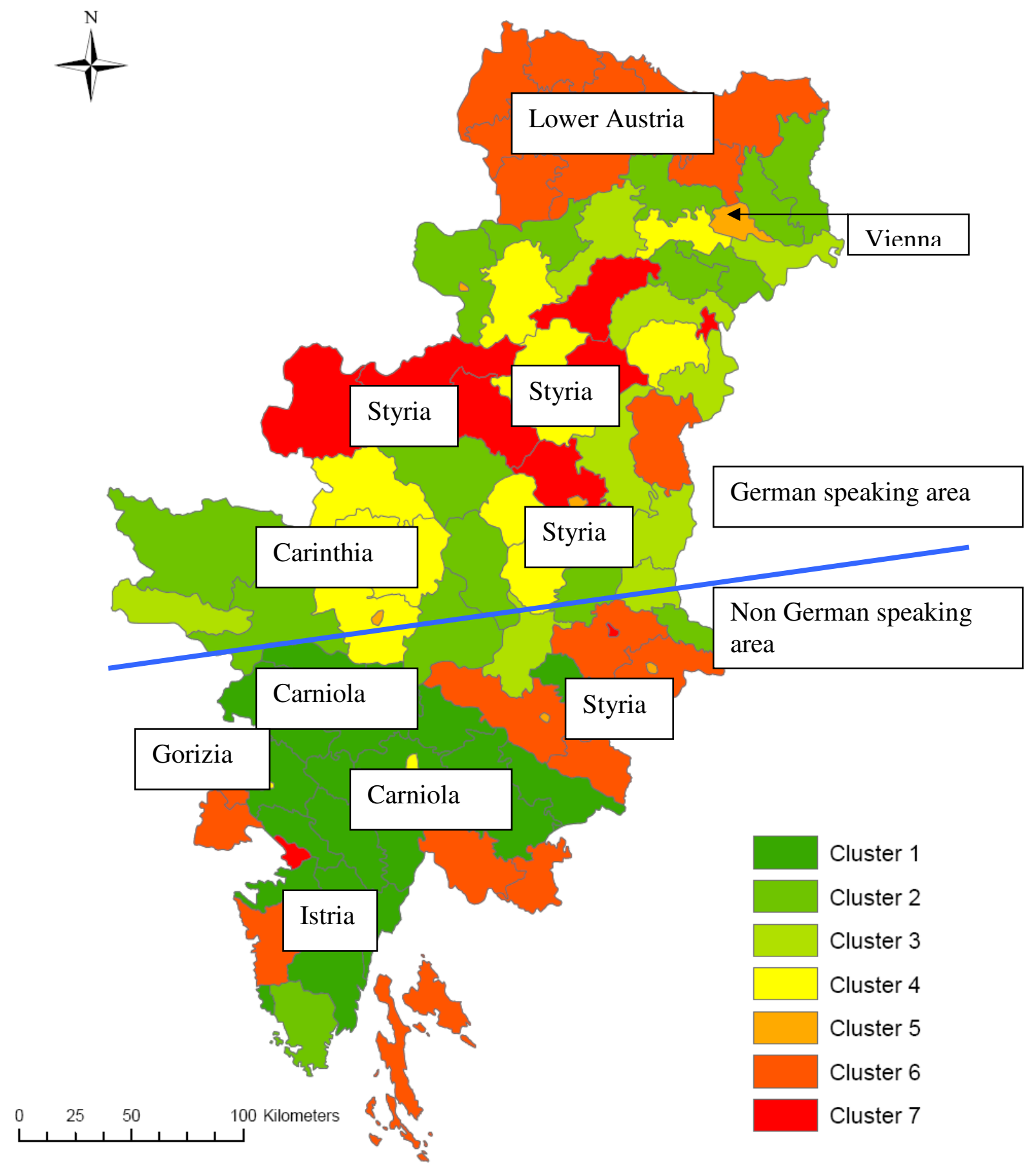

*See also the appendix, Graphs 11 to 17. 
Thus, we can summarize the different regional patterns as follows:

- The smallholders (winegrowers and very small farmers in northern Lower Austria and fishermen and Mediterranean agrarians on the Istria islands) started with a very high level of fertility in the 1870s, which fell markedly starting in the 1880s, but as a gross decline only. Finally the decision to have less chidren followed the economic argument of not having enough ressources to care for more children, facing a strongly declining infant mortality (Cluster 6 especially).

- The big cattle-raising and foresting farmers operating in a conservative, agrarian niche system started with a low level of fertility, and then saw an increase in fertility, partly due to a social catch-up process, and partly in order to compensate for out-migration (Clusters 2 and 4).

- The industrialized areas also started with a relatively low level of fertility, and then underwent a sharp rise (social catch-up process initiated by the inmigrants from the conservative, agrarian countryside) in the $1890 \mathrm{~s}$, and had clearly entered a transition process starting about 1900, triggered by higher costs for the children (education) and a quantity-quality tradeoff (Cluster 7).

- The small grain farmers started with a relatively low level, which was maintained with a slight decline (Cluster 3 especially), induced by the challenges of market oriented production, which needed investment into the farm and not in the children.

- The urban areas started with the lowest level of fertility, but a persistent decline is discernible in the 1890s (Cluster 5), due to a declining infant mortality, followed by a quantity-quality tradeoff, like in industrial regions.

- The small farmers, who often worked part-time as peddlers, in Carniola, Gorizia, and Istria always had the highest levels of fertility showing almost no gross or net decline (Cluster 1). They followed the pre-modern pattern, having more children in good times and less in bad ones, and now the times got better.

The main criteria are socioeconomic, though an ethnic effect remains. This effect emerged as an "ethnicization" of significant, widespread, and common poverty among the predominantly agrarian population. It is important to note that only the gross fertility decline has been measured in this analysis of trends and serial regional patterns. 
What does poverty mean $?^{10}$ We do not have concrete income data for the districts, but some other data provide strong, though indirect, indicators of poverty. We will use six criteria to measure poverty in the districts:

- the occupational distribution and the female participation,

- the units of heavy livestock per farm,

- the production of agrarian goods (grain and milk),

- the tax rate per capita,

- the savings rate per capita, and

- levels of illiteracy.

Table 13: Female illiteracy and Spearman's coefficients in 1900 and 1910

\begin{tabular}{|c|c|c|c|c|c|c|}
\hline \multirow[t]{2}{*}{ Variables } & \multicolumn{6}{|l|}{ FILL } \\
\hline & $\begin{array}{l}1900 \\
\text { all }\end{array}$ & $\begin{array}{l}1900 \\
\text { G }\end{array}$ & $\begin{array}{l}1900 \\
\mathrm{NG}\end{array}$ & $\begin{array}{l}1910 \\
\text { all }\end{array}$ & $\begin{array}{l}1910 \\
G\end{array}$ & $\begin{array}{l}1910 \\
\mathrm{NG}\end{array}$ \\
\hline MFR & $.402 * *$ & .231 & -.086 & $.487 * *$ & $.345 * *$ & .048 \\
\hline NMFR & $-.273^{*}$ & $.364 * *$ & -.230 & -.199 & $.442 * *$ & -.119 \\
\hline PMf20-44 & $.380 * *$ & $-.441 * *$ & $.645 * *$ & $.427 * *$ & $-.479 * *$ & $.638 * *$ \\
\hline AMf & $-.673 * *$ & .027 & $-.732 * *$ & $-.776 * *$ & -.131 & $-.810 * *$ \\
\hline
\end{tabular}

MFR=marital fertility rate, NMFR=non-marital fertility rate, PMf20-44=percentages of females married among 20-44-year-old females, AMf=female age at marriage, FILL=female illiteracy rate; $\mathrm{G}=$ German-speaking; NG=non-German-speaking; ** = highly significant, * = significant

Table 13 reveals a methodical problem. When dealing with interregional comparisons, we must always take into account that we are crossing borders and moving through different systems that consist of a network of interrelated patterns, structures, customs, traditions, manners, rules, etc.

In our case, we have detected that the German-speaking north and the non-Germanspeaking south partially represented different systems, which was also evident in the different fertility patterns. The north basically had lower marital fertility, higher nonmarital fertility, and a less egalitarian nuptiality system than the south. Illiteracy is, undoubtedly, a factor in poverty.

\footnotetext{
${ }^{10}$ We do not mean the official poor, those who were fed by the official poor relief.
} 
Female illiteracy is a good criterion for measuring these regional disparities, because high levels of illiteracy can only be found in the south, particularly in the far south only. Additionally, we can assume that illiteracy in the non-German south was not just a social, but also a political phenomenon. During the census, the household heads were asked if the household members, and especially the children, could write and read. Obviously the officials and the natives understood the question to mean writing and reading the German language, which was the official language in Austria. It is not conceivable that in 1910 in Istria almost 50\% of the females (older than age 10) were illiterate, as the data indicate. Either the respondents refused to answer positively, or they refused to send their children to a school where they would learn to read and to write German, the language of the oppressors. In Carniola $11.5 \%$ of the females were registered as illiterate (no writing, no reading), while in Gorizia the figure was $17.3 \%$, and in Trieste (town and surroundings) it was $10 \%$. In Istria, by contrast, the Austrian Statistics tables indicate that a full $46 \%$ of females are illiterate. Another set of statistics show that, in Istria Crown land, almost $60 \%$ of the children were not enrolled in primary school in 1910. The 1910 census indicates that $5.4 \%$ of the population was German-speaking in Carniola, compared with $1.8 \%$ in Gorizia and $3.3 \%$ in Istria.

In 1867, the Hungarians achieved their "compromise" with Austria, which meant they gained sovereignty in many issues, including the official language. The Slavic population never gained these rights. The so-called "Sprachenregelung" of Premier Badeni, which would have granted the right to use the Czech language in offices, never really existed. It was introduced in 1897 and suspended in 1899 following heavy protests among nationalist German-speaking people. Moreover, it was only intended to be applied to Bohemia and Moravia, and to the Czechs only, and not to the Slavic and Italian people in the south.

Thus, the finding of an overall correlation of $.402 * *$ between marital fertility and female illiteracy in 1900 (.487** in 1910) does not necessarily prove the thesis that high fertility was coupled with a lack of education among women. This value appeared because in the non-German-speaking south we found that a higher illiteracy rate was accompanied by a higher marital fertility rate. We are convinced that in 1910 in Istria, the majority of the children older than age 10 could read and write, but in Italian or Croatian, not in German. Moreover, marital fertility was higher in Carniola, but illiteracy was much lower there than in Istria. What does literacy mean? We cannot distinguish what they did read, if they could. We can only say, that there was 
no chance to change to a better job without being literate, but we cannot conclude that literacy automatically entailed a progress. Let's think of the peddlers from Inner Carniola, they could uphold themselves and their families, but they did not advance.

After computing the coefficient for German- and non-German-speaking areas separately, we found that the correlation between illiteracy and high fertility became much lower, and the results even suggest that this was a real social issue in the German-speaking areas only.

Mirroring that complication is the issue of non-marital fertility. The analysis showed a low and negative overall correlation between illiteracy and non-marital fertility, and that this correlation can be found among the non-German-speaking population only.

Non-marital fertility was not low because illiteracy was high in these areas and vice versa, but rather because these areas had an egalitarian nuptiality system coupled with stronger taboos on out-of-wedlock fertility, for both the mother and the child. In the German-speaking areas, illiteracy was positively associated with non-marital fertility. Again, only in these areas were illiteracy and non-marital fertility connected as social issues, mainly due to the non-egalitarian nuptiality strategies in agrarian niche systems, and, to a lesser extent, subordinate female occupation in the second and third sectors.

We could also conclude that there was a very high overall correlation between marriage age and illiteracy by noting that illiterate women married earlier, but, again, this correlation was found in the non-German-speaking areas only. While illiteracy was higher there, the marriage age was generally lower, for literate as well as illiterate women.

The percentages of married women aged 20 to 44 is completely disrupted due to the existence of two nuptiality systems. The overall correlation was relatively low, although highly significant, and positive. However, only the non-German-speaking regions showed a positive and highly significant correlation, again because of the egalitarian nuptiality system. In the non-German-speaking areas, by contrast, the percentages of married women and illiteracy were negatively correlated.

Table 14 contains a lot of data, some of it perplexing. We will attempt to explain it step by step.

The impact of HLU, which is an indirect indicator of the size of a farm because grain farms always had been much smaller ${ }^{11}$, weakened. In fact, raising cattle required

\footnotetext{
${ }^{11}$ This was the case since the distribution of land in the late Middle Ages, heavy livestock needs pastures and in the mountainous areas graining was not advantageous due to the climate.
} 
having permanent farmhands, and this agrarian ecotype thus involved a social hierarchy, a niche system, and non-egalitarian marriage patterns (Mitterauer 1986 and 1995).

Table 14: Marital fertility and Spearman's correlations in 1900 and 1910

\begin{tabular}{|c|c|c|c|c|c|c|}
\hline & all & $G$ & $\mathrm{NG}$ & all & $\mathrm{G}$ & NG \\
\hline & \multicolumn{3}{|l|}{1900} & \multicolumn{3}{|l|}{1910} \\
\hline HLU & $-.476 * *$ & $-.279 *$ & -.298 & $-.359 * *$ & -.123 & -.119 \\
\hline TAX & $-.566 * *$ & $-.647 * *$ & $-.446^{*}$ & $-.686 * *$ & $-.765 * *$ & $-.638 * *$ \\
\hline SAV & $-.509 * *$ & $-.609 * *$ & -.480 & $-.417 * *$ & $-.433 * *$ & $-.650 *$ \\
\hline GRAIN & $-.261 *$ & .246 & .088 & $-.291 *$ & .075 & .316 \\
\hline MILK & .265 & $.514 * *$ & $.507 *$ & .115 & $.473^{* *}$ & $.593 * *$ \\
\hline AGR & $.668^{* *}$ & $.708^{* *}$ & $.443 *$ & $.762 * *$ & $.869^{* *}$ & $.659 * *$ \\
\hline NAGR & $-.668 * *$ & $-.708 * *$ & $-.443^{*}$ & $-.762 * *$ & $-.869 * *$ & $-.659 * *$ \\
\hline WAGR & $.638^{* * *}$ & $.667 * *$ & $.437 *$ & $.675^{* * *}$ & $.865^{* *}$ & $.723 * *$ \\
\hline WNAGR & $-.627 * *$ & $-.736^{* *}$ & -.326 & $-.703 * *$ & $-.820 * *$ & $-.512 * *$ \\
\hline
\end{tabular}

All=overall correlation, $\mathrm{G}=$ in German-speaking areas only, $\mathrm{NG=in} \mathrm{non-German-speaking} \mathrm{areas} \mathrm{only,}$ $\mathrm{HLU}=$ heavy livestock unit per farm, TAX=income tax rate per adult $(>14), \mathrm{SAV}=$ savings rate per adult, GRAIN: wheat and grain in kilograms per capita, MILK= milk in liters per capita, AGR= percentages of persons belonging to agricultural structures (incl. children and older people), NAGR=percentages belonging to non-agricultural structures (incl. children and older people), WAGR=percentages of women, belonging to agricultural structures among all women 14-60 years old, WNAGR=percentages of women, belonging to non-agricultural structures among all women 14-60 years old,$*=$ significant, $* *=$ highly significant

The decrease in the coefficient indicates there was a slight degree of social modernization in these areas. Surprisingly, we find a negative - but not significant impact on marital fertility in the non-German-speaking countries, which were undoubtedly dominated by a more egalitarian marriage pattern. The number of larger cattle-raising farms was almost certainly much lower in these areas, but in some districts, like Windischgraz/Slovenj Gradec in Lower Styria, these farms had been more numerous. Again, marital fertility appears to have been a social issue.

GRAIN production had no significant impact on marital fertility, but milk production obviously had an effect. This impact most likely mirrors the HLU effect. Marriage options increased everywhere, especially in conservative agrarian areas, and these patterns were coupled with cattle-raising, which entails milk production, as noted 
above. The increase in marital fertility in these regions cannot have been triggered by the sudden appearance of the use of animal's milk for feeding the infants, and especially in the non-German-speaking south, breastfeeding was common.

The values of AGR and NAGR mirror each other perfectly because they are derived from percentages. The increasing and contradictory AGR and NAGR indicate the presence of a growing gap between agrarian and non-agrarian patterns of demographic behavior, production, etc. This effect also appears when we are considering female occupation (WAGR and WNAGR; s. Table 15 also), which, however, shows a regional peculiarity. Whereas in the German-speaking countries the non-agrarian employment of women had a stronger (1900) or similarly strong (1910) negative impact on marital fertility relative to the positive impact of the agrarian occupation, the opposite was the case in the non-German-speaking countries. Obviously, due to a lower level of industrialization, or of de-agrarization, the negative impact on marital fertility was lower, and was even lower than the positive impact of agrarian employment. However, the increase in the values indicate the opening of a gap. This gap becomes especially striking when we look at the TAX and SAV in the non-German-speaking, mostly agrarian south. The lower the tax and savings rates per capita, the higher the marital fertility, and this effect became stronger over time.

Table 15: Percentages of male and female occupation in non-agrarian sectors (among all adult males and females aged 14-60)

\begin{tabular}{|l|l|l|l|l|}
\hline & $\begin{array}{l}1891- \\
1900\end{array}$ & $\begin{array}{l}1901- \\
1910\end{array}$ & $\begin{array}{l}1891- \\
1900\end{array}$ & $\begin{array}{l}1901- \\
1910\end{array}$ \\
\hline & \multicolumn{1}{|l|}{ Male } & \multicolumn{2}{l|}{ Female } \\
\hline Vienna & 96,8 & 95,6 & 40,6 & 45,7 \\
\hline Wine Quarter (Lower Austria) & 48,6 & 47,4 & 17,4 & 20,9 \\
\hline Industrial Upper Styria & $\mathbf{7 1 , 1}$ & $\mathbf{7 5 , 1}$ & $\mathbf{2 4 , 0}$ & $\mathbf{3 2 , 2}$ \\
\hline Agrarian Upper Styria & $\mathbf{4 7 , 3}$ & $\mathbf{5 0 , 9}$ & $\mathbf{2 4 , 4}$ & $\mathbf{2 7 , 8}$ \\
\hline Carinthia Midlands & $\mathbf{4 7 , 7}$ & $\mathbf{5 4 , 7}$ & $\mathbf{2 0 , 6}$ & $\mathbf{2 8 , 8}$ \\
\hline Southern Styria & 28,5 & 34,0 & 16,7 & 20,4 \\
\hline Lower Styria & 22,5 & 27,9 & 10,1 & 14,3 \\
\hline Inner Carniola & 30,8 & 36,0 & 14,7 & 23,2 \\
\hline Trieste & 92,7 & 92,4 & 34,0 & 36,7 \\
\hline Istria Islands & 29,1 & 32,4 & 12,8 & 13,3 \\
\hline
\end{tabular}

Bold: regions with a catch-up process; italics: non-German-speaking areas 
We have seen that there is a high positive correlation between smaller agrarian units and percentages of agrarian smallholders on the one hand, and marital fertility and nuptiality on the other. The marriage age was lower in these areas. It is also clear that, especially in the non-German-speaking south, these small units and smallholders were predominant.

Looking at the impact of factors such as inheritance rules, life expectancy, and the demand for workers on nuptiality, the marriage age, and marital fertility is useful only when studying the agrarian system, at least since the prohibition on child labor in industry. In our period of research (1869 to 1913), the farms were not divided more frequently in the southern areas, but the units were already much smaller due to partitioning in earlier times. Life expectancy for the women was not lower. Thus, these factors cannot have been the reasons for the lower marriage age. Since the agrarian units were smaller, the demand for labor cannot have been the reason for the higher marital fertility. Because infant mortality was lower in the south, high infant mortality cannot have been a reason for the high levels of fertility.

So what, aside from social attitudes, accounts for the desire among young people to be married, or better said, for the desire among the elder having the young people married? Poverty may have been a factor ("What else remains to the poor than love?"), as marriage allowed couples to share their resources, and they had less to lose by making a commitment.

We cannot go into the debate on stem families and nuclear families and household/family forms (Szoltysek and Gruber 2011, Hammel and Laslett 1974, Seccombe 1992) because we do not deal with nominative data. Yet for the Crown lands there are some data from the aggregated statistics indicating that the household/family structures were not influenced by these different social systems of nuptiality, marriage age, and marital fertility. Based on our knowledge that the Crown land of Carinthia had an agrarian non-egalitarian system and Carniola did not, we can use some data for these Crown lands.

Table 16 shows clearly that, in Carniola Crown land, the system was more egalitarian. The members of the agrarian substrata, like workers and day laborers, are significantly more likely to be married and living in their own households. The category of related farmhands, who lived in the household of the related head, are just as very less likely to be married. This is a strong indicator that these persons, most of them siblings, did not change the household structure to a joint structure in Carniola. 
Table 16: Percentages of married men (20-40 years old) along social position in household, 1900

\begin{tabular}{|l|l|l|l|l|l|l|}
\hline & Heads & $\begin{array}{l}\text { White- } \\
\text { collar } \\
\text { workers }\end{array}$ & $\begin{array}{l}\text { Workers } \\
(=\text { farmhands })\end{array}$ & $\begin{array}{l}\text { Day } \\
\text { laborers }\end{array}$ & $\begin{array}{l}\text { Related } \\
\text { farmhands }\end{array}$ & $\begin{array}{l}\text { Other } \\
\text { relatives* }\end{array}$ \\
\hline $\begin{array}{l}\text { Carinthia } \\
\text { Agriculture }\end{array}$ & 82,3 & 55,6 & 6,6 & 24,1 & 4,7 & 11,1 \\
\hline $\begin{array}{l}\text { Carniola } \\
\text { Agriculture }\end{array}$ & 93,2 & 53,9 & 17,7 & 47,9 & 4,0 & 8,4 \\
$*$ "without & \multicolumn{2}{|c|}{ own profession," mostly children and older people } \\
\hline
\end{tabular}

Therefore, we can conclude that, in the agrarian households in Carniola, there was only one married couple. The more egalitarian nuptiality system was especially important for workers and day laborers, having their own households. The percentages for the other relatives suggest the existence of some stem families.

Nevertheless, we do not believe, that stem families were concepted, rather they came into reality. We guess, that it was considered advantageous by the farmholders as subsidients to clear inheritance so long as they are alive. In lucky cases, when the parents lived longer than expected, a stem family appeared. Howsoever, if the creation of a longer lasting stem family was really intended, marriage age of the predefined heir must have been low, due to a low life expectany of his parents. Yet in those areas were we can find more frequent numbers of stem families, marriage age was not low enough and life expectancy was not high enough to guarantee the surviving of a stem family over a longer period.

\section{Fertility, nuptiality, and migration}

The study of the fertility and marriage behavior of migrants has become one of the most interesting fields of demography in the last decade, as it focuses on the four main theories of selection, socialization, adaptation, and disruption (Kulu 2003, Moreels and Vandezande and Matthijs 2010). In GAFP, migration was measured with the help of information about the regional origin (=region of birth) of a district's population in the census years from 1869 up to 1910 . We do not know the local place of origin of the in-migrants, but the categories of the regional origins of the inmigrants had been staggered along the next-higher administration level. Thus, those 
born locally were counted first, followed by those who came from (=born in) the same district, those came from another district of the same Crown land, those who came from another Crown land, and, finally, those who came from abroad.

To a certain degree, this graduated approach mirrors the distance of in-migration. The values for the years 1869 and 1880 are not completely valid because they do not reflect the place of birth of an in-migrant, but rather of his so-called "Zuständigkeit" (right of residence), which was connected to the place of birth. The problem with this approach is that children were automatically assigned the Zuständigkeit of their parents, even when they were born in the place they lived. The censuses after 1890 counted the place of birth as the place of origin.

The numbers in Table 17 strongly support the disruption thesis. The higher the percentage of residents who were born locally, the higher the level of marital fertility in a district. The coefficient becomes negative, when there was substantial inmigration. The problem is that, after 1900, marital fertility in Vienna and in the industrial areas had already started to fall significantly.

Table 17: Marital fertility and migration, Spearman correlations

\begin{tabular}{|l|l|l|l|l|l|l|}
\hline $\begin{array}{l}\text { Birth and } \\
\text { residence }\end{array}$ & all & G & NG & all & G & NG \\
\hline & 1900 & \multicolumn{5}{|l|}{} \\
\hline SameCom & $.800^{* *}$ & $.777^{* *}$ & .325 & $.816^{* *}$ & $.776^{* *}$ & .365 \\
\hline Same Dis & $-.506^{* *}$ & -.115 & .365 & $-.345^{* *}$ & $.338^{*}$ & .416 \\
\hline SameCro & $-.710^{* *}$ & $-.750^{* *}$ & -.387 & $-.710^{* *}$ & $-.690^{* *}$ & $-.435^{*}$ \\
\hline DiffCro & $-.623^{* *}$ & $-.584^{* *}$ & $-.445^{*}$ & $-.716^{* *}$ & $-.779^{* *}$ & $-.534^{* *}$ \\
\hline
\end{tabular}

SameCom=born and resident in the same community, SameDis=born in another

community of the same district, SameCro=born in another district of the same Crown land, DiffCro=born in another Crown land; $*$ =significant, $* *=$ highly significant; all categories are measured as percentages of the whole resident population, both sexes; all=overall correlation, $\mathrm{G}=\mathrm{German}$ speaking areas, $\mathrm{NG}=$ non-German-speaking areas

In 1900 in Leoben (Industrial Upper Styria), the most industrialized district, only 19\% of all the adult (14-60-year-old) males and $22 \%$ of the adult females were occupied in agriculture. In 1890, marital fertility in Leoben was 211.3, and the SameCom amounted to $32.4 \%$; while in 1900 , marital fertility had reached its peak of 255.3 and the SameCom still was very low, at $30.5 \%$. Among the residents who were not locally born, the SameCro grew from $24 \%$ in 1890 to $26.5 \%$ in 1900 , and the DiffCro 
increased from $17.9 \%$ in 1890 to $21.1 \%$ in 1900 . Thus for Vienna and industrial regions the disruption theory does not fit, at least not for these decades, due to the skijump story and the social catch-up process on the one hand and due to the ongoing fertility decline on the other, pretending that in-migration would have been guilty for the fertility decline.

Again, we have to consider systemic regional peculiarities as the overall coefficients are often misleading, mixing up everything in a huge pot. To better understand the special situation of the industrial district of Leoben, let us remember that there was a city of the same name, with about 20,000 inhabitants in 1900, but in which the industrial sites were spread over the whole district, and in which there was no shortage of housing, unlike in big, crowded cities like Vienna. In Vienna, marital fertility and the percentages of in-migrants from more distant locations had been decreasing since the 1890 s, but the percentages of residents who were born locally grew from $43 \%$ to $49 \%$, which indicates that the disruption theory did not really match the situation in the big cities also.

Following the coefficients in Table 18, we again observe that migration appears to have disrupted nuptiality, to the extent that the in-migrants were single. Yet Vienna and the industrial regions like Leoben again defy this general trend.

Between 1869 and 1910, the percentages of married women markedly increased, in Vienna from 42,5 to $48,6 \%$ and in Leoben from $47.4 \%$ to $57 \%$, while the percentages of in-migrants (not locally born) increased.

Table 18: Nuptiality ${ }^{1}$ and migration in 1900 and 1910, Spearman's correlations

\begin{tabular}{|l|l|l|l|l|l|l|}
\hline $\begin{array}{l}\text { Birth and } \\
\text { residence }\end{array}$ & All & G & NG & All & G & NG \\
\hline & 1900 & \multicolumn{5}{|l|}{} \\
\hline SameCom & $.572 * *$ & .214 & $.623 * *$ & $.567 * *$ & .245 & $.601 * *$ \\
\hline Same Dis & $-.742 * *$ & $-.630 * *$ & $-.531 *$ & $-.729 * *$ & $-.657 * *$ & $-.497 *$ \\
\hline SameCro & $-.407 * *$ & -.140 & $-.642 * *$ & $-.447 * *$ & -.169 & $-.687 * *$ \\
\hline DiffCro & -.201 & .088 & -.370 & $-.276^{*}$ & -.038 & -.368 \\
\hline
\end{tabular}

SameCom=born and resident in the same community, SameDis=born in another community of the same district, SameCro=born in another district of the same Crown land, DiffCro=born in another Crown land; *=significant, $* *=$ highly significant; all of the categories are measured as percentages of the whole resident population, both sexes; all=overall correlation, G=among German-speaking areas only, NG=among non-German-speaking areas only; ${ }^{1}=$ percentages of married women aged 20-44 among all women in these years of age 
Paradoxically, the overall coefficient did not grow in proportion to the distance of the in-migrant's birth region; instead, the coefficient was lowest for the in-migrants in the non-German-speaking areas who were from more distant locations. In the Germanspeaking areas, the negative coefficient was weakened in inverse proportion to the distance of in-migration. This finding obviously can be attributed to the large capital of Vienna especially which attracted a lot of people from farther away who intended to stay, to marry and have children in order to increase their social status. Those who came from nearer obviously often intended to stay single, and were fluctuating, merely moving to another industrial site. In the non-German-speaking areas, the high negative values for the in-migrants from the same Crown land may be because many of these migrants were peddlers. The census was taken in December, which is the time when the peddlers were on the road. In any case, with only aggregate data available, we can only speculate about the reasons. We cannot differentiate between "traditional" forms of migration-like those related to peddling, working as a farmhand, or getting married — which often involved moving to a different district of a Crown land; and "new" migration, especially to the urban centers and the industrial sites, which frequently involved moves from more distant locations. Regardless, the great majority of the residents who were not born locally (in-migrants) came from either the same district or another district of the same Crown land, even in Vienna and in the industrial regions. This leads to another effect indicating migration and marital fertility or nuptiality which can be detected in the serial comparison of the percentages of locally born residents and in-migrants.

In general, the percentages of locally born residents were decreasing in Table 19, except in Vienna. In the non-German-speaking, agrarian countries these portions were much higher, except in the port city of Trieste. The argument is that, when there is an increasing percentage of residents who were locally born and an equally increasing migration effect, we have to assume that in-migrants contribute to the fertility in the town. This was the case in Vienna. In the port city of Trieste the effect was even stronger, because the portions of locally born residents decreased whilst the migration effect arised.

If the percentage of locally born people decreases, as was the case for all of the agrarian regions, and the out-migration also increases, we must, paradoxically, conclude that the in-migrants tended to stay, while the locally born tended to go. There were always two types of migrants: those who stayed at the first target place, and those who moved frequently (Hochstadt 1999). 
Table 19: Percentages of locally born and in-migrants, 1880 to 1910

\begin{tabular}{|l|l|l|l|l|}
\hline Meso-regions & 1880 & 1890 & 1900 & 1910 \\
\hline $\begin{array}{l}\text { Vienna } \text { migration effect }^{* *} \\
\text { Wine Quarter (Lower Austria) }\end{array}$ & 34,6 & 43,1 & 46,4 & 48,8 \\
& 0,5 & 0,9 & 1,0 & 1,1 \\
\hline Industrial Upper Styria & 0,4 & 0,2 & 0,0 & $-0,1$ \\
\hline Agrarian Upper Styria & 39,3 & 36,6 & 35,4 & 36,3 \\
& 0,6 & 0,7 & 0,6 & 0,3 \\
\hline Carinthia Midlands & 54,6 & 47,8 & 44,5 & 45,5 \\
& -0.0 & $-0,4$ & $-0,2$ & $-0,4$ \\
\hline Southern Styria & 58,4 & 52,3 & 48,1 & 46,6 \\
& $-0,1$ & $-0,1$ & $-0,4$ & $-0,1$ \\
\hline Lower Styria & 59,1 & 48,6 & 49,3 & 47,7 \\
& $-0,1$ & $-0,2$ & $-0,5$ & $-0,2$ \\
\hline Istria Islands & 69,4 & 56,4 & 58,7 & 59,9 \\
& $-0,4$ & $-0,4$ & $-0,8$ & $-0,8$ \\
\hline Trieste & 89,5 & 79,4 & 79,6 & 78,6 \\
& $-0,4$ & $-0,6$ & $-0,9$ & $-1,0$ \\
\hline & 46,9 & 61,0 & 59,6 & 57,0 \\
& $-0,4$ & $-0,6$ & $-0,7$ & $-0,8$ \\
\hline
\end{tabular}

Locally born residents, in percentage of the civil population; ${ }^{* *}$ annual means for the $1870 \mathrm{~s}, 1880 \mathrm{~s}$, 1890 s, and 1900s, computed with the help of a starting population in 1869, a linear interpolated population until the next census, the annual live births and the deaths. The values show the percentages of in-migrating civil persons in comparison to the whole civil population, with a minus indicating a loss and out-migration. Italics: non-German-speaking countries

The first group, especially those who migrated from more distant locations, therefore contributed to fertility, and hence to the city's population growth, in two ways. The fluctuating migrants did not, or to illegitimacy at most.

Table 20 shows that in-migration did not play a major role relative to births and deaths in any region, including in those regions with high levels of in-migration. The percentages of deaths declined everywhere, which indicates a lowering of mortality. The percentages of births did change depending on the regional system. In the cities 
of Vienna and Trieste, the component of natural reproduction became weaker over time. In those regions that experienced a social catch-up process in response to the widening of options to marry, the percentages of births increased, which compensated for out-migration also. In the agrarian regions of the non-German speaking south, the percentages did not change, which indicates the presence of a solidified structure suffering from seasonal out-migration, which likely was dampening fertility (Quaranta 2011) and from permanent emigration, absorbing the growth which could have been gained by the reduction in the death rate.

Table 20: Percentages of population movement ingredients ${ }^{1}$, mean per decade

\begin{tabular}{|l|l|l|l|l|l|l|}
\hline & \multicolumn{4}{l}{$1871-1880$} & \multicolumn{2}{l}{$1901-1910$} \\
\hline & $\mathrm{B}$ & $\mathrm{D}$ & $\mathrm{M}$ & $\mathrm{B}$ & $\mathrm{D}$ & $\mathrm{M}$ \\
\hline Vienna & 53,3 & 41,5 & 5,2 & 48,8 & 32,2 & 19,0 \\
\hline Wine Quarter (Lower Austria) & 52.0 & 41,7 & 6,3 & 51,4 & 35,9 & $-12,7$ \\
\hline Industrial Upper Styria & $\mathbf{4 9 , 2}$ & $\mathbf{4 3 , 1}$ & $\mathbf{7 , 7}$ & $\mathbf{5 6 , 5}$ & $\mathbf{3 6 , 1}$ & $\mathbf{7 , 4}$ \\
\hline Agrarian Upper Styria & $\mathbf{5 0 , 0}$ & $\mathbf{4 6 , 5}$ & $\mathbf{- 3 . 5}$ & $\mathbf{5 4 , 9}$ & $\mathbf{3 6 , 5}$ & $\mathbf{- 8 , 6}$ \\
\hline Carinthia Midlands & $\mathbf{5 0 , 9}$ & $\mathbf{4 4 , 9}$ & $\mathbf{- 4 , 2}$ & $\mathbf{5 4 , 9}$ & $\mathbf{3 8 , 1}$ & $\mathbf{- 7 , 0}$ \\
\hline Southern Styria & $\mathbf{5 2 , 0}$ & 43,7 & $-4,3$ & $\mathbf{5 2 , 6}$ & 43,3 & $-4,1$ \\
\hline Lower Styria & 52,4 & 41,6 & $-6,0$ & 52,6 & 43,3 & $-4,1$ \\
\hline Inner Carniola & 52,4 & 41,7 & $-5,9$ & 52,2 & 34,3 & $-13,5$ \\
\hline Trieste & 46,2 & 42,6 & 11,2 & 43,7 & 32,9 & 23,4 \\
\hline Istria Islands & 53,4 & 40,5 & $-6,1$ & 53,9 & 35,4 & $-11,7$ \\
\hline
\end{tabular}

Bold: regions with a catch-up process, italics: non-German speaking areas, ${ }^{1}$ : births (B) plus deaths (D) and migrating $(\mathrm{M})$ persons=100, a minus for the migrating persons indicates a negative balance

Did cities grow for natural reasons or due to in-migration?

This question is still being debated (Williamson 1990; Hochstadt 1999; Lawton and Lee 2002). Austrian Statistics stated in 1900 that Vienna was experiencing strong population growth due to a surplus of births, but that Trieste and Graz, for example, were seeing only moderate growth in their natural populations. ${ }^{12}$ Vienna, the largest city, with about two million residents in 1910, indeed showed a marked increase in the percentage of locally born people (see Table 19). It can generally be assumed that the birth surplus was the major source of growth in all of the cities, but that growth was lower in the smaller cities. These findings also indicate that in-migrants,

\footnotetext{
${ }^{12}$ Oesterreichische Statistik, Vol. LXIII/1. Vienna 1902: pp. XXff.
} 
especially those from more distant locations, contributed to fertility and natural reproduction. The disruption effect of migration was clearly lower for those people (see Table 18) and stronger for the fluctuating, no matter if in industry or in agrarian work.

Graph 7 shows clearly that, even in Vienna, the number of live births was always much higher than the numbers of in-migrants, and that general population growth came mainly from generation renewal.

Graph 7: In-migrants and natural growth in Vienna

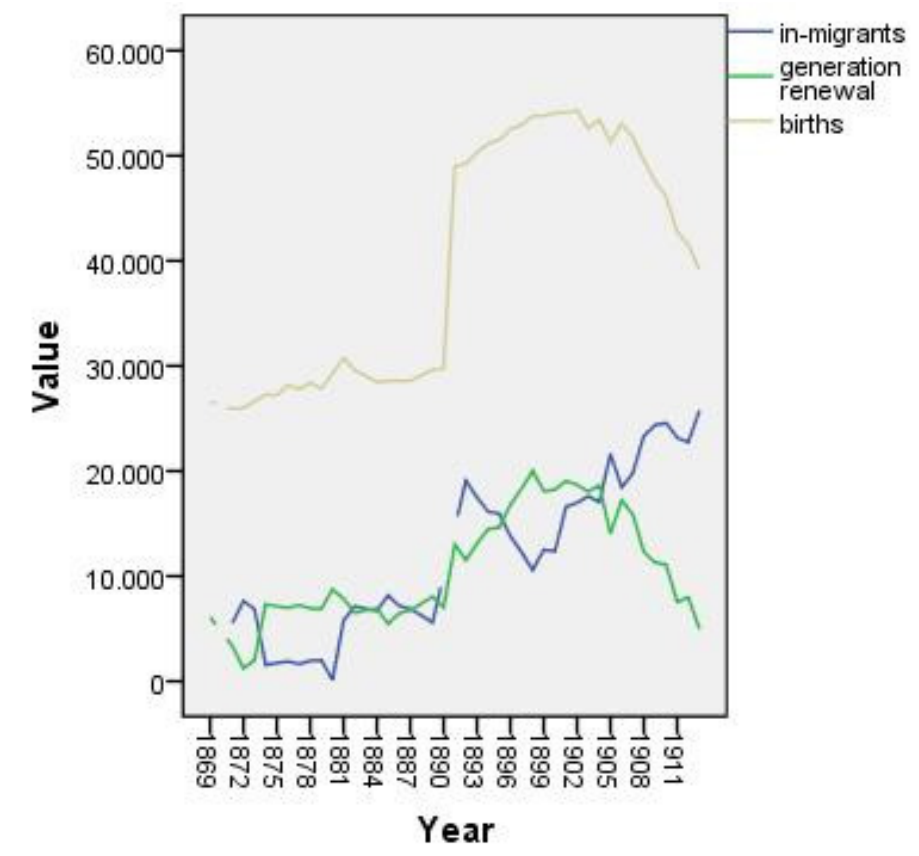

The gap started to close only after a net decline in marital fertility had started in the 1900s. It should, however, be noted that in-migrants most likely contributed to natality, including to its decline. Generation renewal and in-migration often passed each other until the onset of a net fertility decline, and natural growth only started to lag behind after that time (ca. 1904). In 1891, Vienna was enlarged to include some populous districts that once lay outside of the city's borders. In all of the other cities, the impact of migration impact had always been higher due to the substantial death rate.

The small town of Marburg/Maribor (s. Graph 8) in Lower Styria, today Slovenia, became an industrial site and a transport hub (railway) in the second half of $19^{\text {th }}$ century. Its population doubled from 13,000 in 1869 to 26,000 in 1910. Mortality in the cities always was distorted by the existence of hospitals, birthing houses, and foundling homes, which increased mortality by cases coming from outside of the city. 
Graph 8: In-migrants and natural growth in Marburg/Maribor town

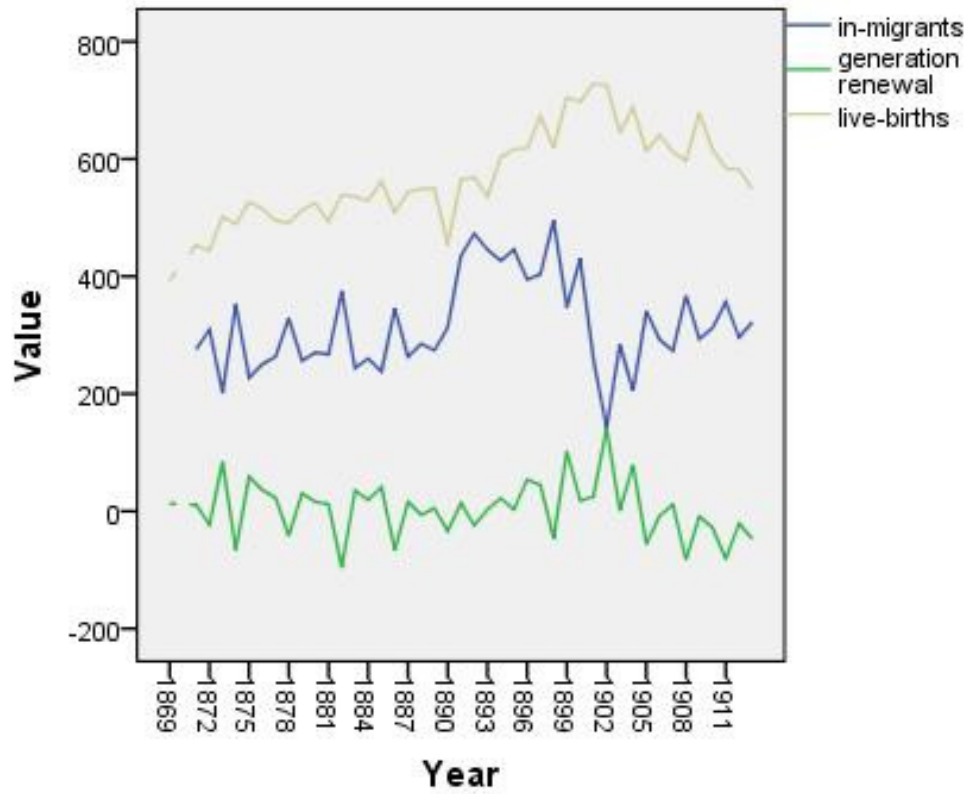

In Marburg, however, there were no such houses, and only a very small hospital. Thus, the low and often negative level of generation renewal indicated that life was dangerous in those kinds of towns due to their less developed medical and sanitary systems (sewage, clean water, etc.) and dirty and risky working conditions. ${ }^{13}$ In Marburg, population growth was a consequence of in-migration. Marburg had a small hospital, but there was none in the surrounding district. The presence of the hospital may have distorted the figures for generation renewal in Marburg to some extent.

Graph 9: In-migrants and natural growth in Waidhofen/Ybbs

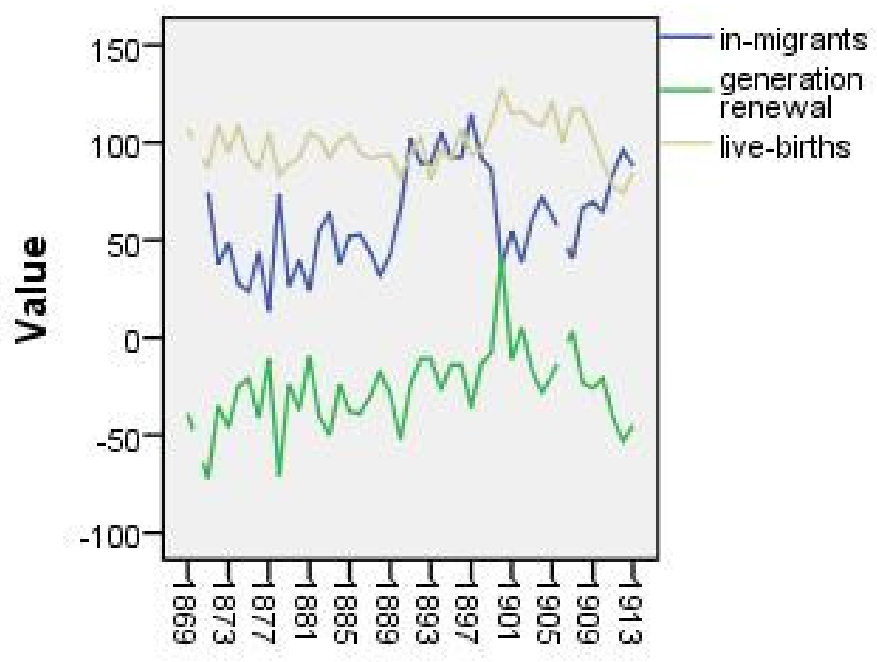

Year

\footnotetext{
${ }^{13}$ Because of problems in the process of industrialization, most of the Austrian cities shared the fate as British cities until the 1870s in the following decades (Szreter and Mooney 1998).
} 
However, the situation was the same in the much smaller town of Waidhofen upon Ybbs in western Lower Austria (s. Graph 9). Even if we assume that 50\% (about 10) of the people dying in the hospital came from outside of the town, generation renewal remained negative or only slightly positive, and there was no net fertility decline. The town grew from 3,500 inhabitants in 1869 to 5,000 in 1910, due to the iron industries. The opposite was the case in the countryside (see Graph 10). Murau was a district in agrarian Upper Styria which was dominated by larger, heavy livestock-raising farmers operating in a niche system. The district experienced out-migration as farmhands left for nearby industrial regions.

Graph 10: In-migrants and natural growth in Murau

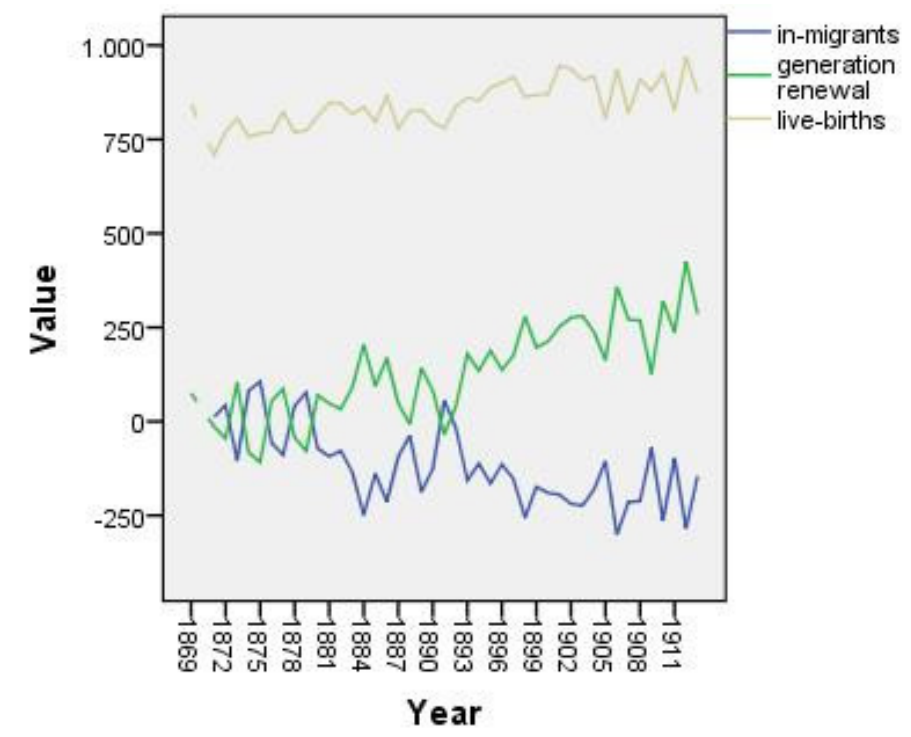

The district's population growth stagnated at about 27,000 inhabitants. Marital fertility grew in response to the loss in workers. But, because the living conditions were clearly better there than in the cities, generation renewal showed a growing positive tendency.

Yet there was also migration in agrarian areas, traditional labor migration of farmhands, day laborers etc., who mostly are not married - the farmhands especially and fluctuating.

Table 21 shows clearly, that marital fertility was negatively connected to in-migration, which supports disruption theory as well as assimilation theory, depending on fluctuation or stability of in-migrants. Yet non-marital fertility was interrelated positively with in-migration, but in agrarian areas only, indicating illegitimacy among fluctuating farmhands especially. Infant mortality was the higher the more of those people were present in agrarian regions. 
Table 21

Migration and non-parametric correlations ${ }^{1}$ in agrarian $^{2}$ and non-agrarian ${ }^{3}$ areas

\begin{tabular}{|c|c|c|c|c|c|}
\hline Year & MF & NonMF & IM & $\mathrm{W}_{\text {married }}$ & $\mathrm{W}_{\mathrm{m} \text {-age }}$ \\
\hline & A $\quad \mathrm{NA}$ & A $\quad \mathrm{NA}$ & A $\quad \mathrm{NA}$ & A $\quad \mathrm{NA}$ & A $\quad \mathrm{NA}$ \\
\hline 1890 & $-.71^{* * *}-.66^{* * *}$ & $\begin{array}{ll}.78^{* * *} & .33\end{array}$ & $.58^{*}-.50^{*}$ & $-.61^{* *}-.61^{*}$ & $.64^{* * *} \quad .12$ \\
\hline 1900 & $-.75^{* * *}-.74^{* * *}$ & $.83^{* *} \quad .26$ & $.56^{* *}-.53^{* * *}$ & $-.66^{* *}-.60^{* *}$ & $.75^{* *} \quad .49^{* * *}$ \\
\hline 1910 &,$- 74^{* * *}-.66^{* * *}$ & $.83^{* * *}-.07$ & $\begin{array}{ll}.55 & -.44^{* * *}\end{array}$ & $-.63^{* *}-.61^{* *}$ & $\begin{array}{ll}.77^{* * *} & .06\end{array}$ \\
\hline
\end{tabular}

$\mathrm{MF}=$ marital fertility, NonMF=non-marital fertility, IM=infant mortality,

$\mathrm{W}_{\text {married }}=$ percentage of married women, 20-44 years old, $\mathrm{W}_{\mathrm{m}-\mathrm{age}}=$ female mean marriage age; $\mathrm{A}=$ agrarian areas, NA=non-agraian areas: ${ }^{1}$ correlation with the portion of resident, but not native born persons in a Political District; ${ }^{2}$ less than $50 \%$ of the peole belong to the agrarian muilieu; ${ }^{3}$ more than $50 \%$ of the people belong to the non-agrarian milieu (due to the occupational statistics of the census)

In urban and industrial regions we can see the opposite, but this effect obviously was triggered by an advanced health care and especially by the export of infants and their deceases from foundling homes in the cities to the countryside. The portions of married women exhibited the same negative correlations in agrarian as well as in nonagrarian areas. It means, that traditional, agrarian migration and new, urban and industrial oriented nigration had a negative impact on nuptilaity. Especially the agrarian farmhands kept single and a lot of the industrial and urban in-migrants were fluctuating. Obviously this fluctuation was less expressed, the farer from the migrants came (s. table 18). The high correlation with female marriage age in the agrarian areas stems from the socio-economic structure: the more in-migrants, the more farmhands, which indicates the existence of an ecotype, consisting of larger, cattle-raising farmers. In this, non-egalitarian agrarian society it was only possible to marry as an owning farmer and in the case of inheritance the heir was already 30 or even older and his bride was not younger than 26. As mentioned, we can find this system in the mountaineous Inner-Alpine regions especially. The high female marriage age has nothing to do with the mostly unmarried farmhands, but their existence as in-migrants is a strong indicator, they are part of this system. 
Returning to the title of the paper, we should point out that, if the area we researched had been shown to have been crossed by the Hajnal line or to have been a transitional zone in terms of demographic patterns, we would have been obligated to reject both concepts. However, our results showed that there were significant differences in nuptiality and marital/non-marital fertility, and that these differences were not incidental and not exceptional, but were significant phenomena, both structurally and regionally.

First: The current Austrian province of Burgenland, the former West Hungary, was a high-fertility area with an average raw birth rate of 39 in the 1890s. During the same period, the adjacent regions in Lower Austria showed values of 34-35 and the Styrian regions on the eastern border had a GR of 28-29. Second: The Lower Austrian Wine Quarter "Weinviertel" was situated on the border to Hungary (today's Slowakia), and had a marital fertility rate of 295 in the 1890s; while in the adjacent southern Industrial Quarter, marital fertility was 269 during the same period. Following the line to the south, we find a corresponding figure of 268 in southern Styria; while just a short distance away in Lower Styria (today northeastern Slovenia), marital fertility amounted to 303 and may have even been rising. This trend became stronger in the far south, in Inner Carniola and Istria. The highest level of marital fertility was found along the Kaser-Mitterauer line. A transitional zone looks different (concerning the geographical settings, see Figure 4.). As we have pointed out, marriage and marital fertility patterns were very strongly influenced by social rules and economic factors. In general, we found higher nuptiality and higher marital fertility in the agrarian regions dominated by smaller farms or smallholders. These regions can be found in the north (Forest Quarter in north-western Lower Austria), far from the MitterauerKaser line and in the east (Wine Quarter in the northeast of Lower Austria), as well as in southern Styria and in the Slovenian-, Italian-, and Croatian-speaking regions in the south. The region of Gorizia, for example, was located in the far east of today's Slovenia, and was among the regions with the highest fertility of those researched in this paper. A more egalitarian marriage system triggered higher nuptiality and higher marital fertility in the agrarian regions, which were dominated by small farms and smallholders. It was merely a coincidence that these regions were situated in the more eastern part of the German-speaking part of this area, leading us from Lower Austria to the south. The non-German-speaking areas in the far south in particular were 
dominated by small farmers and smallholders who had to leave home regularly to work as peddlers in order to earn enough money to feed their families. Even the Reher line works only partially for the same reasons as those used above in rejecting the Hajnal and Mitterauer-Kaser lines. Thus, we prefer to talk about socio-regional patterns and not about geographical patterns characterized by a net of longitudes and latitudes in which everything can be located.

Where these regional systems had their origins we cannot definitively say. We can, however, assume that these are systems that consist of social and economic rules influenced by those of the regional states, and that were eventually linked together and condensed into cultural forms. We cannot know whether the Slovenes, the Italians, and the Croats always cultivated a more egalitarian nuptiality system, and especially whether they did so because they were Slovenes, etc. Similarly, we have no way of knowing whether mountainous conditions necessarily or exclusively led to raising cattle as an agrarian ecotype, or whether cattle-raising necessarily led us to non-egalitarian nuptiality systems. Empirically, however, some clear trends can be discerned. The question of how many servants a farm needed or could afford cannot be answered by using a general economic model, as there is more than one way to satisfy the demand for labor, even if we can reduce the problem to feudalist or postfeudalist structures. L. Berkner (1977), for example, has shown that very small farmers in the Forest Quarter in Lower Austria replaced farmhands with their own children; A. Fauve-Chamoux (1995 and 2006) has pointed out that conservative, nonegalitarian agrarian communities in the mountains took care of individuals who did not reach the status of a landowner due to the practice of niche strategies; and C. Sumnall (2009 and 2010) has shown that illegitimacy was an alternative for landless farmhands, and that illegitimate children were eventually accepted by the owners. Poverty among agrarian owners or tenants, a lower marriage age, high nuptiality, and high marital fertility were strongly correlated. It is possible that poverty and the lack of (affordable) opportunities for advancement rendered the issue of quantity-quality tradeoff irrelevant, and thus lowered the cost of raising children. Before 1910, a net decline in marital fertility was observable only in Vienna, but even there the decrease did not occur before the very late 1890s. Among the smallholders (especially among the very small farmers in the Forest Quarter in Lower Austria, the winegrowers in Lower Austria, and the fishermen and Mediterranean agrarians on the Istria islands) there was an early (since the 1870s) and persistent gross decline. After about 1900, the industrial regions also experienced a slight net decline. 
While it is necessary to differentiate between groups and areas, we have to be careful when drawing lines through countries, dividing and allocating humans, because these lines cover moving structural elements, and can create the impression that populations or circumstances are unchangeable. That could lead to the development of negative prejudices.

In examining the reasons for the fertility decline or its absence, we could look at issues related to infant mortality (epidemiological theory), the costs and benefits of having children (market economy theory), the quantity-quality tradeoff (also an economic theory), or socio-cultural factors (Doepke 2005, Becker and Murphy and Tamura 1990, Coale \& Watkins 1986). We would expect to find a quantity-quality tradeoff only in a market-oriented economy, and assume that this tradeoff should be independent of the decline in infant mortality, appearing as a real net decline in fertility. Obviously this was the case only in Vienna, where the tradeoff was accompanied by a decline in infant mortality $(<1)$ starting in the 1890 s, which significantly accelerated starting about 1900.

In the smaller cities, we can observe a gross fertiliy decline only, after a decrease in infant mortality. In the smallholder societies (winegrowers in Lower Austria and Mediterranean agrarians on the Istria islands), which experienced a spatial problem in having to perform an extensive land utilization, we can observe a gross decline, but no net decline. Thus, when there was a decline in infant mortality, the people living in these areas knew they could not feed more surviving children. In the conservative, agrarian, non-egalitarian systems in the mountains (larger farms with heavy livestock and servants) a social catch-up process occurred, with fertility increasing in response to the low marital fertility and nuptiality in earlier times, and to out-migration and demand for labor.

In the industrial areas, we can also observe this social catch-up process among permanent in-migrants (-though we cannot make assumptions about the fertility of temporary in-migrants, like brick-workers from Bohemia and Moravia in Vienna)from the conservative, agrarian countryside. Yet obviously the decline in infant mortality halted this process, introducing the problem of costs and benefits. Eventually, a tradeoff could have happened, to the extent that there was a demand for more educated and skilled workers in the industries. We assume that this was not the case in the heavy-metals industry, which dominated the industrial sites in our research area. In the non-German-speaking south, we found the highest level of marital fertility, and almost no gross decline. This was because infant mortality was relatively 
low there due to the widespread practice of breastfeeding, which did not start to decline before World War I. In Carniola, for example, infant mortality ratio was about 19 out of 100 in the 1880s (but 30 in Lower Austria), and it was about 18 after 1910 (but 21 in Lower Austria). Obviously there was no need to reduce fertility. The social system guaranteed egalitarian nuptiality, as well as a certain degree of equality in poverty. Thus it was not a "cultural" factor, as posited by Coale \& Watkins 1986, but a socio-cultural one.

Doepke 2005 concluded his analysis on infant and child mortality and fertility decline as follows: "The results suggest that factors other than declining infant and child mortality are responsible for the large decline in net reproduction rates observed in industrialized countries over the last century;" and: "All of the models discussed in this paper lead to the same conclusion: declines in child mortality lower total fertility rates, but do not cause decreases in net fertility." We strongly agree with these findings, especially for the very first period of a systemic and structural decline in fertility. A decrease in infant/child mortality obviously challenged fertility behavior and led to a gross decline, but a net decline can only occur when there are persistent changes in economic living conditions, such as the introduction of a market-oriented economy; the creation of non-agrarian jobs in industry and then in the third sector; growth in the demand for more educated and skilled people; an increase in the cost of housing, education, etc., relative to the cost of basic nutrition; a process of social modernization, or more chances for more people to advance; and a process of secularization.

We cannot, however, agree with the following statement by Doepke 2005: "since mortality decline lowers the cost of every child equally, it favors quantity over quality and slows fertility decline." We believe that we have to distinguish between the costs of ensuring that an infant or a child will survive the risky early years of lifegenerally, the first five years-and the cost of providing children with secondary education in later years. Presumably, the first category of costs, which allow children to survive and receive a primary education, may have played a less important role. Since migration played an enormous role in the period of the onset of fertility decline, we also have to consider life plans. Did an in-migrant choose to stay, and then get married and have children? Or did the in-migrant choose to stay temporarily, while waiting for a better opportunity elsewhere? The latter group supposedly did not marry and may have contributed to out-of-wedlock births. Yet in this case, we could assume a balanced situation, because most of these in-migrants had also been unmarried in 
their places of origin. Moreover, it may be problematic to compare birth rates and infant mortality rates, as Doepke 2005 did. This is because the birth rate depends on the existence and the behavior of potential mothers, but the IMR depends on the existence of children who have already been born. Therefore, we should use the same population, namely the women at risk for both events, a birth and a death, when estimating a net fertility decline, as was done in this paper.

\section{References}

Bacher, J. and Pöge, A. and Wenzig, K. (2010)(Eds.). Clusteranalyse. Anwendungsorientierte Einführung in Klassifikationsverfahren. München: Oldenbourg.

Becker, G.S and Murphy, K.M. and Tamura, R (1990). Human Capital, Fertility, and Economic Growth. Journal of Political Economy 98:12-37.

Becker, P. (1990). Leben und Lieben in einem kalten Land. Sexualität zwischen Ökonomie und Demographie. Das Beispiel St. Lambrecht, Steiermark 1600-1850. Campus: Frankfurt, New York.

Berkner, L. (1990). The Stem Family and the Development Cycle of the Peasant Household: An Eighteenth-Century Austrian Example. In:

J. Komlos (Ed.), Economic Development in the Habsburg Monarchy and in the Successor States (pp.167-184). New York: Columbia University Press.

Coale, A. J. and S. C. Watkins (eds.) (1986). The Decline of Fertility in Europe. Princeton: Princeton University Press.

Demeny, P. (1972). Early fertility decline in Austria-Hungary: a lesson in demographic transition. In: David V. Glass and Roger Revelle (eds.), Population and Social Change. London: Eward Arnold: 153-172.

Derosas, R. and van Popel, F. (2006)(Eds.). Religion and the Decline of Fertility in the Western World. New York: Springer.

Doepke, M. (2005). Child mortality and fertility decline: Does the Barro-Becker model fit the facts? Journal of Population Economics 18/2:337-366.

Doblhammer, G. and Rodgers, J.L and Rau, R. (2000). Seasonality of birth in nineteenth- and twentieth-century Austria. Biodemography and Social Biology 47/3$4,: 201-217$.

Dribe, M. (2009). Demand and supply factors in the fertility transition: a county-level analysis of age-specific marital fertility in Sweden, 1880-1930. European Review of Economic History 13: 65-94. 
Dribe, M. and Putte, B.van de (2011). Marriage seasonality and the industrious revolution: southern Sweden, 1690-1895. Economic History Review 2011: 1-24.

Dribe, M. and Scalone, F. (2011). Socioeconomic status and net fertility in the demographic transition: Sweden in 1900 - a preliminary analysis. Paper for the annual meeting of the Social Science History Association, Boston, November 2011.

Ehmer, J. (1991). Heiratsverhalten, Sozialstruktur, ökonomischer Wandel. Göttingen: Vandenhoeck \& Ruprecht.

Ehmer, J. (2004). Bevölkerungsgeschichte und Historische Demographie, 1800-2000. München: Oldebourg.

Exner, G. (1999). Fertilitätsrückgang auf der Ebene der politischen Bezirke im österreichischen Teil der Habsburgermonarchie in den Jahren 1880 bis 1910: eine historisch-demographische Analyse. [Wien, Institut für Demographie, unpublished research report, 1999]

Fauve-Chamoux, A. (1995). The stem family, demography and inheritance. The social frontiers of auto-regulation. In Richard L. Rudolph (Ed.), The European peasant family and society. Historical studies (pp.86-113). Liverpool: Liverpool University Press.

Fauve-Chamoux, A. (2006). Family reproduction and stem-family systems. From Pyrenean valleys to Norwegian farms. The History of the Family, 11, 171-184.

Fauve-Chamoux, A. (2011). European Illegitimacy Trends in Connection with Domestic Service and Family Systems (1545-2001). Romanian Journal of Population Studies 2011/2: 8-45.

Hammel, E.A. and Laslett, P. (1974). Comparing household structure over time and between cultures. Comparative Studies in Society and History 16 (1974): 73-109.

Hochstadt, S. (1999). Mobility and Modernity. Migration in germany, 1820-1989. Ann Arbor: The University of Michigan Press.

Hoem, J.M. and Mureşan, C. (2011). The Total Marital Fertility Rate and Its Extensions. European Journal of Population 27: 395-412.

Kaser, K. (2000). Macht und Erbe:Männerherrschaft, Besitz und Familie im östlichen Europa (1500 - 1900). Wien [u.a.]: Böhlau.

Kurmanowytsch, H. (2002). Das Grazer Gebärhaus von seinen Anfängen 1764 bis 1914. Graz: Master Thesis.

Kulu, H. (2003). Migration and Fertility: Competing Hyphotheses re-examined. MPIDR Working paper WP 2003-035. 
Landsteiner, E. and Langthaler, E. (1997). Ökotypus Weinbau: Taglöhner- oder Smallholder-Gesellschaft. In: Institut für Wirtschafts- und Sozialgeschichte, Universität Wien (Ed.), Wiener Wege der Sozialgeschichte. Themen - Perspektiven Vermittlungen. Wien: Böhlau: 183-224.

Lawton, R. and Lee, R. (2002)(eds.).Population and Society in Western European Port-Cities, c. 1650-1939. Liverpool: Liverpool University Press.

Mitterauer, M. (1983). Ledige Mütter. Zur Geschichte illegitimer Geburten in Europa. Beck: München.

Mitterauer, M. (1986). Formen ländlicher Familienwirtschaft. Historische Ökotypen und familiale Arbeitsorganisation im österreichischen Raum. In: Josef Ehmer und Michael Mitterauer (eds.), Familienstruktur und Arbeitsorganisation in ländlichen Gesellschaften. Wien: Böhlau: 185-323.

Mitterauer, M. (1995). Peasant and non-peasant family forms in relation to the physical environment and the local economy. In: Richard L. Rudolph.(Ed.), The European peasant family and society. Liverpool: Liverpool University Press: 26-49.

Mitterauer, M. (2004). Warum Europa? Mittelalterliche Grundlagen eines Sonderwegs. Beck: München.

Moreels, S. and Vandezande, M. and Matthijs, K. (2010). Fertility in the port city of Antwerp (1846-1920). A detailed analysis of immigrants' spacing behaviour in an urbanizing context. Working paper of the Scientific Research Community Historical Demography WOG/HD/ 2010-14. Leuven: Centre for Sociological Research (CeSO). Pfister, Ch. (2007). Bevölkerungsgeschichte und Historische Demographie, 15001800. München: Oldenbourg.

Quaranta, L. (2011). Agency of Change: Fertility and Seasonal Migration in a Nineteenth Century Alpine Community. European Journal of Population issue 2704: 457-485.

Reher, D.S. (1998). Family Ties in Western Europe: Persistent Contrasts. Population and Development Review 24: 203-224.

Rigler, P. and Rozman, I. (2010). From the House into the World. The life of Woodenware making and Peddling Families in the Ribnica Valley in the $20^{\text {th }}$ Century. Ribnica.

Seccombe, W. (1992). A Millenium of Family Change. Feudalism to Capitalism in Northwestern Europe. London: Verso. 
Sumnall, C. (2009). There's no such thing as sin in the Alps. Some Reflections on the historical demography of illegitimacy in Carinthia after 1868", Transylvanian Review XVIII, Supplement to conference: Demographic changes in the time of Industrialisation: 195-224.

Sumnall, C. (2010). “The Hills Are Alive With The Sound Of Bastards!” Illegitimacy and its social reception in the Gurk Valley, Austria, c.1880 to 1940. In: M-P. Arrizabalaga, I. Bolovan, M. Eppel, J. Kok, M-L. Nagata (eds.), Many Paths to Happiness. Studies in Population and Family History: a Festschrift for Antoinette Fauve-Chamoux, Amsterdam: Askant: 560-575.

Szoltysek, M. (2007). Central European household and family systems, and the ,Hajnal-Mitterauer' line. The parish of Bujakow $\left(18^{\text {th }}-19^{\text {th }}\right.$ centuries $)$. The History of the Family 12: 19-42.

Szoltysek, M. (2008). Three kinds of preindustrial household formation system in historical Eastern Europe: A challenge to spatial patterns of the European family. History of the Family 13: 223-257.

Szoltysek, M. and Gruber, S. (2011). Stem Families, Joint Families and the European Pattern: What Kind of a Reconsideration Do we Need? Journal of Family History 37/1: 105-125.

Szreter, S. and Mooney, G. (1998). Urbanization, Mortality, and the Standard of Living Debate: New Estimates of the Expectation of Life at Birth in NineteenthCentury British Cities. Economic History Review LI,1: 84-112.

Teibenbacher, P. (2010). Natural population movement and marriage restrictions and hindrances in Styria in the $17^{\text {th }}$ to $19^{\text {th }}$ centuries. The History of the Family 14: 292308.

Vandezande, M. and Mandemakers K. and Kok J. (2011). The impact of Kin Coresidence on Survival Chances of Infants and Children in the Netherlands, 1863-1909. Romanian Journal of Population Studies 2(2011): 139-160.

Wetherell, Ch. (2001). Another Look at Coale's Indices of Fertility, $\mathrm{I}_{\mathrm{f}}$ and $\mathrm{I}_{\mathrm{g}}$. Social Science History 25/4: 589-608.

Williamson, J.G. (1990). Coping with City Growth During The British Industrial Revolution. Cambridge: Cambridge University Press. 


\section{Appendix}

Regional trends in marital fertility

Graph 11: Marital fertility trends in Leoben and Lilienfeld (Cluster 7)

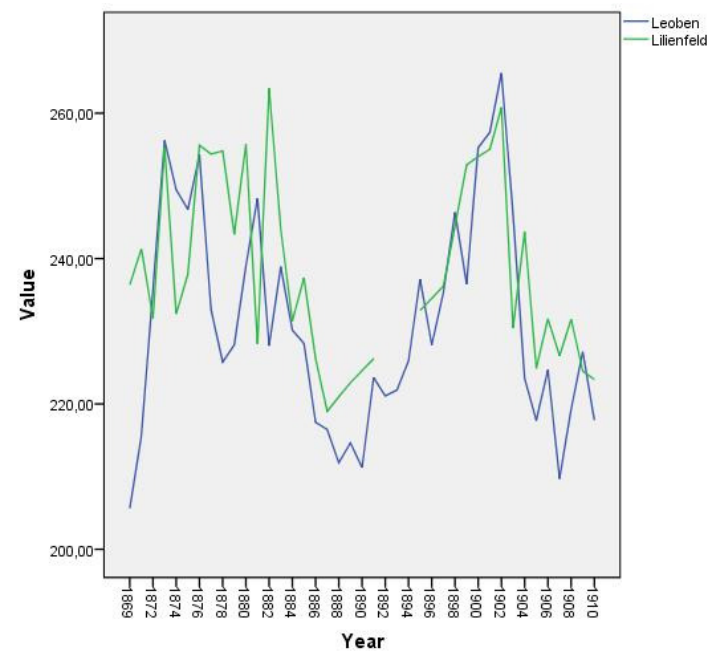

Graph 12: Marital fertility trends in Adelsberg and Pisino-Mitterburg (Cluster 1)

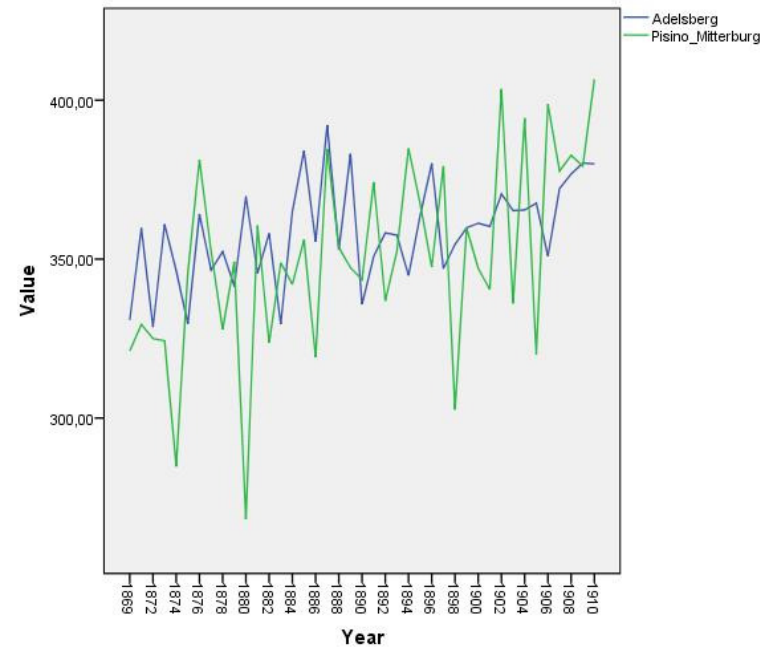

Graph 13: Marital fertility trends in Mistelbach and Lussin (Cluster 6)

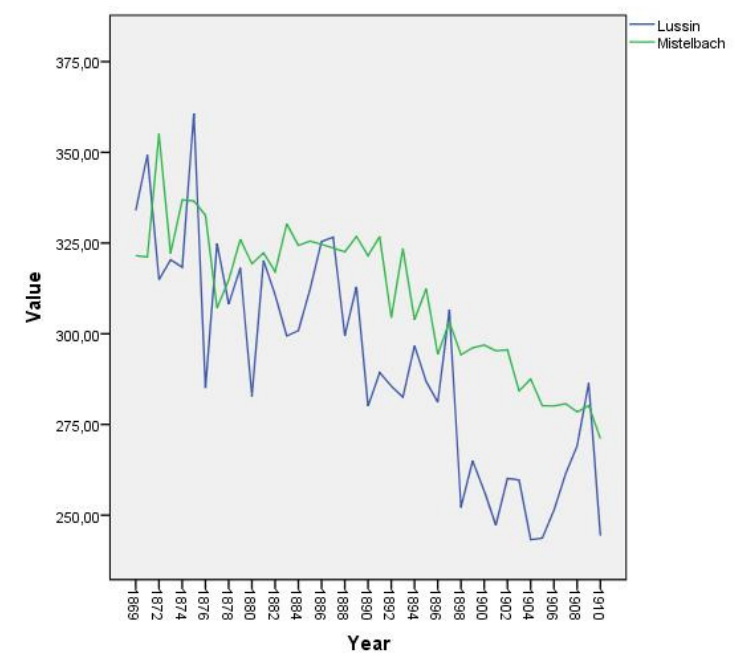


Graph 14: Marital fertility trends in Murau and St.Veit (Cluster 4)

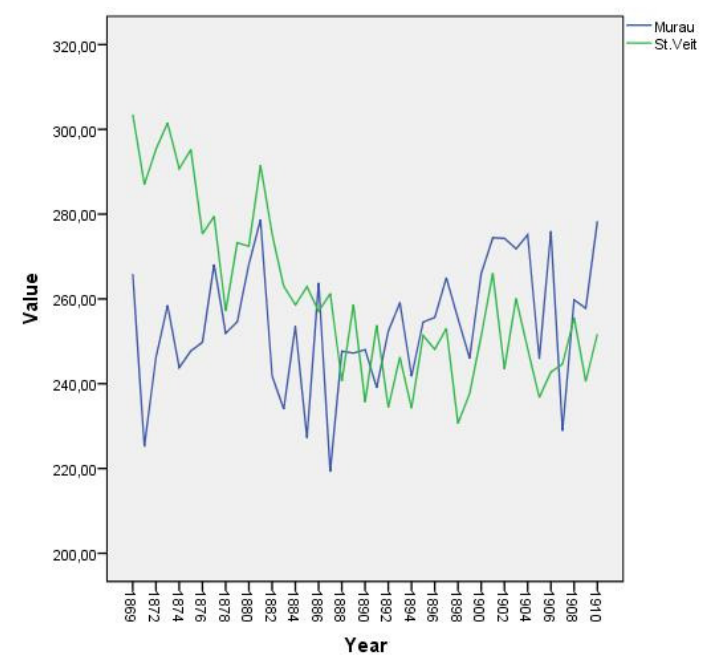

Graph 15: Marital fertility trends in Völkermarkt and Wolfsberg (Cluster 2)

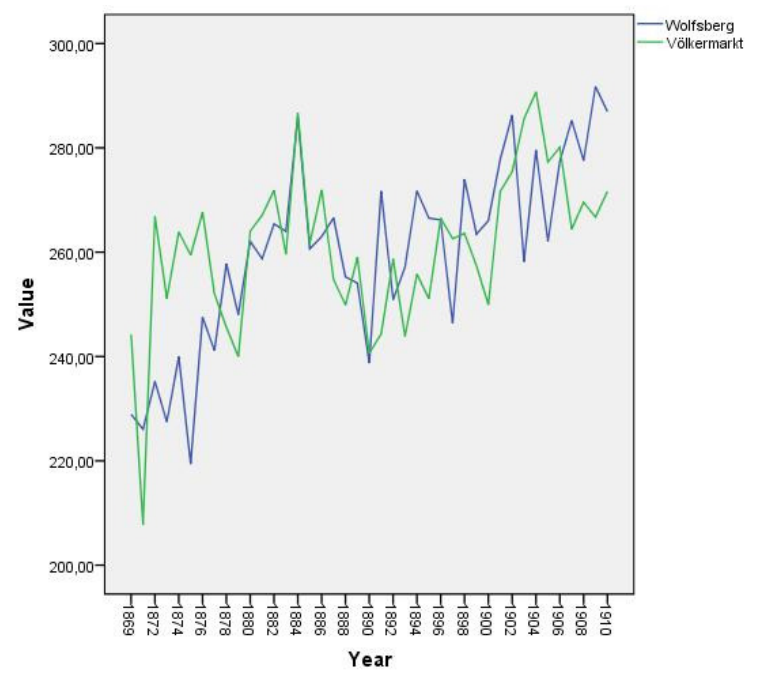

Graph 16: Marital fertility trends in the Wr. Neustadt and surroundings and St.Pölten town and surroundings (Cluster 3)

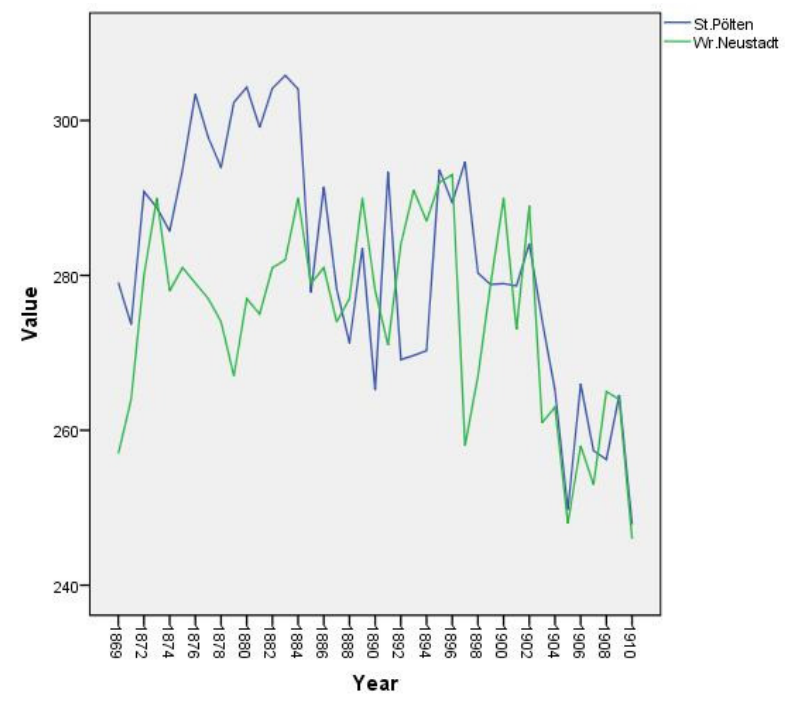


Graph 17: Marital fertility trends in Vienna and Waidhofen upon Ybbs (Cluster 5)

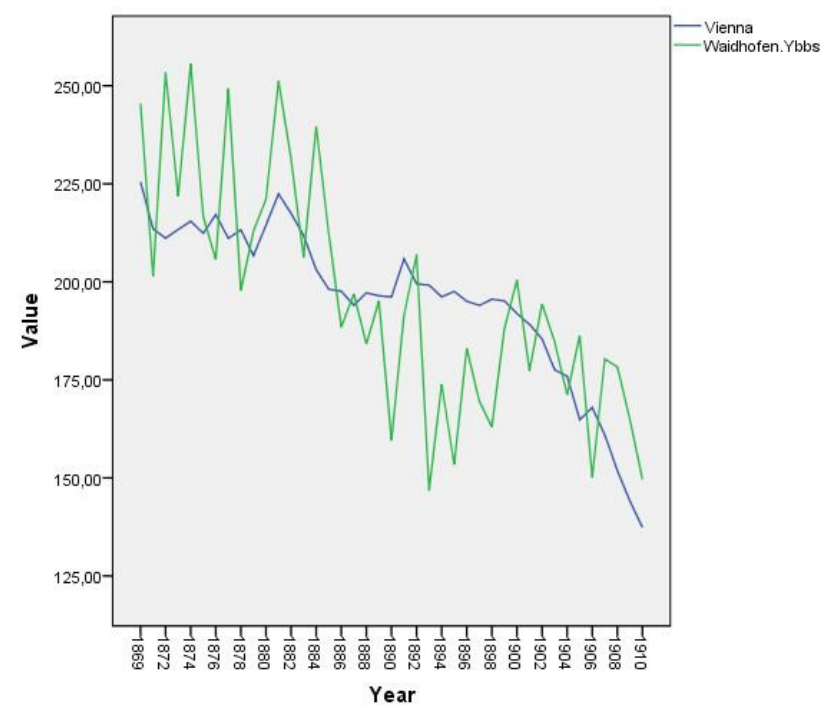

\section{Legend to Fig. 4:}

Lower Austria: 1 Vienna town, 2 Wr.Neustadt town, 3 Industrieviertel/Industrial Quarter, 4 Mostviertel/Cider Quarter, 5 Waldviertel/Forest Quarter, 6 Weinviertel/ Wine Quarter. Styria: 7 Graz town, 8 Cilli town, 9 Marburg town, 10 Pettau town, 11 Agrarian Upper Styria Styria, 12 Industrial Upper Styria, 13 Styria Midlands, 14 Southern Styria, 15 Lower Styria. Carinthia: 16 Klagenfurt town, 17 Carinthia West, 18 Carinthia Midlands, 19 Carinthia East. Carniola: 20 Laibach town,

21 Upper Carniola, 22 Lower Carniola, 23 Inner Carniola. Gorizia: 24 Gorizia town, 25 Gorizia North, 26 Gorizia South. Trieste: 27 Trieste town and surroundings. Istria: 28 Rovigno town, 29 Istria land, 30 Istria islands. Bold lines: borders of the provinces/units or Crown lands. The blue line marks the linguistic and ethnic border between German and non-German Austrians. Parts of southern Carinthia were mixed. I owe a debt of gratitude to Diether Kramer from GAFP for producing all the maps. 
Fig. 4: Meso-regions (MERL)

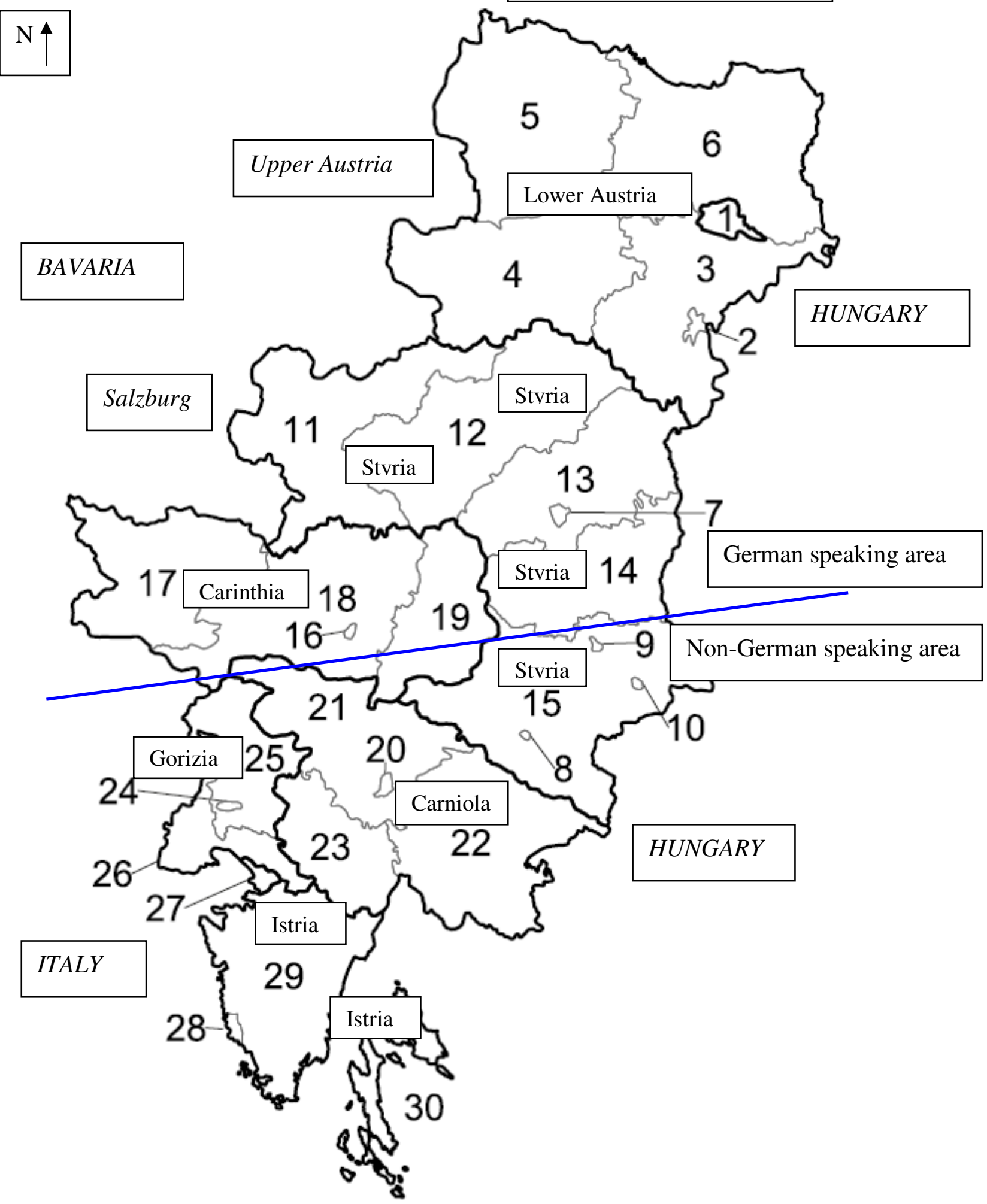


Table 22: Political Districts, Meso-regions and Units/Provinces*/Crown lands

\begin{tabular}{|c|c|c|}
\hline Political District & Meso-region & Unit/Crown land \\
\hline Adelsberg/Postojna & Inner Carniola & Carniola \\
\hline Amstetten & Cider Quarter & Lower Austria \\
\hline Baden & Industrial Quarter & Lower Austria \\
\hline Bruck an der_Leitha & Wine Quarter & Lower Austria \\
\hline Bruck an der_Mur & $\begin{array}{l}\text { Industrial Upper } \\
\text { Styria }\end{array}$ & Styria \\
\hline Capo d' Istria/Koper & Istria land & Istria \\
\hline Cilli/Celje Stadt_ & Lower Styria & Styria \\
\hline Cilli/Celje Surroundings & Lower Styria & Styria \\
\hline Deutschlandsberg & Southern Styria & Styria \\
\hline Feldbach & Southern Styria & Styria \\
\hline Floridsdorf & Wine Quarter & Lower Austria \\
\hline Gmünd & Forest Quarter & Lower Austria \\
\hline Gonobitz/Slovenske Konjice & Lower Styria & Styria \\
\hline Görz/Gorizia/Gorice Town_ & Görz Town & Gorizia \\
\hline Görz/Gorizia/Gorice Surroundings & Gorizia North & Gorizia \\
\hline Gottschee/Kočevje & Lower Carniola & Carniola \\
\hline Gradisca/Goriška/Gradišče & Gorizia South & Gorizia \\
\hline Graz Town & Graz Town & Styria \\
\hline Graz Surroundings & Styria Midlands & Styria \\
\hline Gröbming & Agrarian Upper Styria & Styria \\
\hline Großenzersdorf & Wine Quarter & Lower Austria \\
\hline Gurkfeld/Krško & Lower Carniola & Carniola \\
\hline Hartberg & Styria Midlands & Styria \\
\hline Hermagor & Carinthia West & Carinthia \\
\hline Hernals & Since 1891, Vienna & Lower Austria \\
\hline Hietzing & Industrial Quarter & Lower Austria \\
\hline Horn & Wine Quarter & Lower Austria \\
\hline Judenburg & $\begin{array}{l}\text { Industrial Upper } \\
\text { Styria }\end{array}$ & Styria \\
\hline Klagenfurt Town & Klagenfurt Town & Carinthia \\
\hline
\end{tabular}




\begin{tabular}{|c|c|c|}
\hline Klagenfurt Surroundings & Carinthia Midlands & Carinthia \\
\hline Korneuburg & Wine Quarter & Lower Austria \\
\hline Krainburg/Kranj & Upper Carniola & Carniola \\
\hline Krems & Forest Quarter & Lower Austria \\
\hline Laibach/Ljubljana Town & Laibach Town & Carniola \\
\hline Laibach/Ljubljana Surroundings & Upper Carniola & Carniola \\
\hline Leibnitz & Southern Styria & Styria \\
\hline Leoben & $\begin{array}{l}\text { Industrial Upper } \\
\text { Styria }\end{array}$ & Styria \\
\hline Liezen & Agrarian Upper Styria & Styria \\
\hline Lilienfeld & Cider Quarter & Lower Austria \\
\hline Littai/Litija & Lower Carniola & Carniola \\
\hline Loitsch/Idrija & Inner Carniola & Carniola \\
\hline Lussin/Lušin & Istria islands & Istria \\
\hline Luttenberg/Ljutomer & Lower Styria & Styria \\
\hline Marburg/Maribor Town & Marburg Town & Styria \\
\hline Marburg/Maribor Surroundings & Lower Styria & Styria \\
\hline Melk & Cider Quarter & Lower Austria \\
\hline Mistelbach & Wine Quarter & Lower Austria \\
\hline Mödling & Vienna region & Lower Austria \\
\hline Murau & Agrarian Upper Styria & Styria \\
\hline Mürzzuschlag & $\begin{array}{l}\text { Industrial Upper } \\
\text { Styria }\end{array}$ & Styria \\
\hline Neunkirchen & Industrial Quarter & Lower Austria \\
\hline Oberhollabrunn & Vienna region & Lower Austria \\
\hline Parenzo/Poreč & Istria land & Istria \\
\hline Pettau/Ptuj & Lower Styria & Styria \\
\hline Pettau/Ptuj Town & Lower Styria & Styria \\
\hline Pisino-Mitterburg/Pazin & Istria land & Istria \\
\hline Pöggstall & Cider Quarter & Lower Austria \\
\hline Pola/Pula & Istria land & Istria \\
\hline Radkersburg & Southern Styria & Styria \\
\hline Radmannsdorf/Radovljica & Upper Carniola & Carniola \\
\hline
\end{tabular}




\begin{tabular}{|c|c|c|}
\hline Rann/Brežice & Lower Styria & Styria \\
\hline Rovigno/Rovinj Town & Istria land & Istria \\
\hline Rudolfswerth/Novo Mesto & Lower Carniola & Carniola \\
\hline Scheibbs & Cider Quarter & Lower Austria \\
\hline Sechshaus & Since 1891, Vienna & Lower Austria \\
\hline Sesana/Sezana & Gorizia South & Gorizia \\
\hline Spittal an der Drau & Carinthia West & Carinthia \\
\hline St.Pölten Town und Surroundings & Cider Quarter & Lower Austria \\
\hline St.Veit & Carinthia Midlands & Carinthia \\
\hline Stein/Kamnik & Upper Carniola & Carniola \\
\hline Triest/Trieste Town & Triest & Trieste \\
\hline Tolmein/Tolmin & Gorizia North & Gorizia \\
\hline Tschernembl/Črnomelj & Lower Carniola & Carniola \\
\hline Tulln & Cider Quarter & Lower Austria \\
\hline Untergänserndorf & Wine Quarter & Lower Austria \\
\hline Veglia/Krk & Istria islands & Istria \\
\hline Villach Town und Surroundings & Carinthia Midlands & Carinthia \\
\hline Voitsberg & Styria Midlands & Styria \\
\hline Völkermarkt & Carinthia East & Carinthia \\
\hline Volosca/Volosko & Istria land & Istria \\
\hline Währing & Since 1891 Vienna & Lower Austria \\
\hline Waidhofen an der Thaya & Wine Quarter & Lower Austria \\
\hline Waidhofen an der Ybbs Town & Waidhofen a.d. Ybbs & Lower Austria \\
\hline Weiz & Styria Midlands & Styria \\
\hline Wien/Vienna Town & Wien/Vienna & Lower Austria \\
\hline Wiener Neustadt Town & Wiener Neustadt & Lower Austria \\
\hline Wiener Neustadt Surroundings & Industrial Quarter & Lower Austria \\
\hline Windischgraz/Slovenj Gradec & Lower Styria & Styria \\
\hline Wolfsberg & Carinthia East & Carinthia \\
\hline Zwettl & Forest Quarter & Lower Austria \\
\hline
\end{tabular}

* Istria, for example, was not a separate Crown land; together with Gorizia and Trieste, it formed a littoral Crown land, but each of the three regions were separate statistical units. Vienna also was not a separate Crown land, but belonged to Lower Austria. 
